NBER WORKING PAPER SERIES

\title{
DISTRIBUTIONAL IMPACTS OF CARBON PRICING: A GENERAL EQUILIBRIUM APPROACH WITH MICRO-DATA FOR HOUSEHOLDS
}

\author{
Sebastian Rausch \\ Gilbert E. Metcalf \\ John M. Reilly \\ Working Paper 17087 \\ http://www.nber.org/papers/w17087
}

\author{
NATIONAL BUREAU OF ECONOMIC RESEARCH \\ 1050 Massachusetts Avenue \\ Cambridge, MA 02138
}

May 2011

This paper grew out of a presentation made by Metcalf at the Fourth Atlantic Workshop on Energy and Environmental Economics held in A Toxa, Spain in July 8 - 9, 2010. The authors thank Tony Smith-Grieco for his invaluable help in assembling the CEX data. We acknowledge support of MIT Joint Program on the Science and Policy of Global Change through a combination of government, industry, and foundation funding, the MIT Energy Initiative, and additional support for this work from a coalition of industrial sponsors. The views expressed herein are those of the authors and do not necessarily reflect the views of the National Bureau of Economic Research.

NBER working papers are circulated for discussion and comment purposes. They have not been peerreviewed or been subject to the review by the NBER Board of Directors that accompanies official NBER publications.

(C) 2011 by Sebastian Rausch, Gilbert E. Metcalf, and John M. Reilly. All rights reserved. Short sections of text, not to exceed two paragraphs, may be quoted without explicit permission provided that full credit, including $\odot$ notice, is given to the source. 
Distributional Impacts of Carbon Pricing: A General Equilibrium Approach with Micro-Data for Households

Sebastian Rausch, Gilbert E. Metcalf, and John M. Reilly

NBER Working Paper No. 17087

May 2011

JEL No. H22,Q54,Q58

\begin{abstract}
Many policies to limit greenhouse gas emissions have at their core efforts to put a price on carbon emissions. Carbon pricing impacts households both by raising the cost of carbon intensive products and by changing factor prices. A complete analysis requires taking both effects into account. The impact of carbon pricing is determined by heterogeneity in household spending patterns across income groups as well as heterogeneity in factor income patterns across income groups. It is also affected by precise formulation of the policy (how is the revenue from carbon pricing distributed) as well as the treatment of other government policies (e.g. the treatment of transfer payments). What is often neglected in analyses of policy is the heterogeneity of impacts across households even within income or regional groups. In this paper, we incorporate 15,588 households from the U.S. Consumer and Expenditure Survey data as individual agents in a comparative-static general equilibrium framework. These households are represented within the MIT USREP model, a detailed general equilibrium model of the U.S. economy. In particular, we categorize households by full household income (factor income as well as transfer income) and apply various measures of lifetime income to distinguish households that are temporarily low-income (e.g., retired households drawing down their financial assets) from permanently low-income households. We also provide detailed within-group distributional measures of burden impacts from various policy scenarios.
\end{abstract}

Sebastian Rausch

Joint Program on the Science

and Policy of Global Change

Massachusetts Institute of Technology

1 Amherst St. (Bldg. E40)

Cambridge, MA 02139

rausch@mit.edu

Gilbert E. Metcalf

Department of Economics

Tufts University

Medford, MA 02155

and NBER

gilbert.metcalf@tufts.edu
John M. Reilly

Joint Program on the Science

and Policy of Global Change

Massachusetts Institute of Technology

1 Amherst St. (Bldg. E40)

Cambridge, MA 02139

jreilly@mit.edu 


\section{INTRODUCTION}

Carbon pricing, whether through a cap and trade system or a tax, can have widely varying distributional impacts. Variation in impacts arises for three reasons. First, households differ in how they spend their income. Carbon pricing will raise the price of carbon intensive commodities and disproportionately impact those households who spend larger than average shares of their income on these commodities. In a general equilibrium setting, carbon pricing also impacts factor prices. Households which rely heavily on income from factors whose factor prices fall relative to other factor prices will be adversely impacted. In the public finance literature on tax incidence, the first impact is referred to as a uses of income impact while the latter a sources of income impact (see, for example, Atkinson and Stiglitz, 1980, for a discussion of incidence impacts). Third, regional differences in the composition of energy sources affect the carbon content of various commodities, most notably electricity.

In previous work, we have used a new general equilibrium simulation model of the U.S. economy (the MIT USREP model) to explore distributional implications of various ways of distributing allowances from a cap and trade system (Rausch et al., 2010b) and alternative schemes for returning revenues from an auctioned cap and trade system or equivalently a carbon tax (Rausch et al., 2010a). This paper is similar in spirit to Rausch et al. (2010a) but employs a variant of the USREP model that endogenously incorporates 15,588 households as individual agents within a general equilibrium framework. This allows us to explore distributional impacts of carbon policy over a number of new dimensions that previously have not been explored.

We find the following. First, the use of revenues that can be raised through carbon pricing affects both the efficiency and equity of the policy. Analyses that focus solely on the impacts of carbon pricing without considering the use of revenues can lead to seriously misleading results. Second, the use of a model with a large number of households allows us to consider distributional impacts over different sub-populations. It also drives home the point that variation in impacts from a carbon pricing policy within sub-groups may swamp the variation across groups. Third, we provide two measures that proxy for lifetime income and find little evidence that the use of annual income biases carbon pricing towards greater regressivity. Finally we find interesting variation across racial and ethnic groups that have not been addressed in the literature to date.

We turn next to some background on the measurement of the burden of carbon pricing. Section three describes the model and the following section presents results. We conclude in section 5 .

\section{BACKGROUND}

Carbon pricing through a cap-and-trade system has very similar impacts to broad based energy taxes - not surprising since over eighty percent of greenhouse gas emissions are associated with the combustion of fossil fuels (U.S. Environmental Protection Agency, 2009). The literature on distributional implications across income groups of energy taxes is a long and extensive one and some general conclusions have been reached that help inform the distributional analysis of carbon pricing. First, analyses that rank households by their annual income find that excise taxes in general tend to be regressive (e.g. Pechman, 1985, looking at excise taxes in general and Metcalf, 1999, looking specifically at a cluster of environmental taxes). 
The difficulty with this ranking procedure is that many households in the lowest income groups are not poor in any traditional sense that should raise welfare concerns. This group includes households that are facing transitory negative income shocks or who are making human capital investments that will lead to higher incomes later in life (e.g. graduate students). It also includes many retired households which may have little current income but are able to draw on extensive savings.

That current income may not be a good measure of household well being has long been known and has led to a number of efforts to measure lifetime income. This leads to the second major finding in the literature. Consumption taxes - including taxes on energy - look considerably less regressive when lifetime income measures are used than when annual income measures are used. Studies include Davies et al. (1984), Poterba (1989, 1991), Bull et al. (1994), Lyon and Schwab (1995) and many others. Most of these studies look at a snapshot of taxes in one year relative to some proxy for lifetime income - often current consumption based on the permanent income hypothesis of Friedman (1957).

The lifetime income approach is an important caveat to distributional findings from annual incidence analyses but it relies on strong assumptions about household consumption decisions. In particular it assumes that households base current consumption decisions knowing their full stream of earnings over their lifetime. While it is reasonable to assume that households have some sense of future income, it may be implausible to assume they have complete knowledge or that they necessarily base spending decisions on income that may be received far in the future. We report results in this paper using both an annual income measure and a lifetime income measure.

Turning to climate policy in particular a number of papers have attempted to measure the distributional impacts of carbon pricing across household income groups. Dinan and Rogers (2002) build on Metcalf (1999) to consider how the distribution of allowances from a cap and trade program affects the distributional outcome. Both these papers emphasize that focusing on the distributional burden of carbon pricing (either a tax or auctioned permits) without regard to the use of the revenue raised (or potentially raised) from carbon pricing provides an incomplete distributional analysis. How the proceeds from carbon pricing are distributed have important impacts on the ultimate distributional outcome.

The point that use of carbon revenues matters for distribution is the basis for the distributional and revenue neutral proposal in Metcalf (2007) for a carbon tax swap. It is also the focus of the analysis in Burtraw et al. (2009b). This latter paper considers five different uses of revenue from a cap and trade auction focusing on income distribution as well as regional distribution. A similar focus on income and regional distribution is in Hassett et al. (2009). This last paper does not consider the use of revenue but does compare both annual and lifetime income measures as well as a regional analysis using annual income. Grainger and Kolstad (2009) do a similar analysis as that of Hassett et al. (2009) and note that the use of household equivalence scales can exacerbate the regressivity of carbon pricing. Finally Burtraw et al. (2009a) consider the distributional impacts in an expenditure side analysis where they focus on the allocation of permits to local distribution companies (LDCs). Rausch et al. (2010b) also investigate the welfare costs of 
allocations to LDCs and find that allocations that lead to real or perceived reductions in electricity prices by consumers have large efficiency costs.

With the exception of the last paper, all of the papers above assume that the burden of carbon pricing is shifted forward to consumers in the form of higher energy prices and higher prices of energy-intensive consumption goods and services. That carbon pricing is passed forward to consumers follows from the analysis of a number of computable general equilibrium (CGE) models. Bovenberg and Goulder (2001), for example, find that coal prices rise by over 90 percent of a \$25 per ton carbon tax in the short and long run (Table 2.4). This incidence result underlies their finding that only a small percentage of permits need be freely allocated to energy intensive industries to compensate shareholders for any windfall losses from a cap and trade program. See also Bovenberg et al. (2005) for more on this issue.

Metcalf et al. (2008) consider the degree of forward shifting, as a result of higher consumer prices and backward shifting, as a result of lower factor returns, over different time periods for a carbon tax policy begun in 2012 and slowly ramped up through 2050. The tax on carbon emissions from coal are largely passed forward to consumers in all years of the policy in roughly the same magnitude found by Bovenberg and Goulder (2001). Roughly ten percent of the burden of carbon pricing on crude oil is shifted back to oil producers initially with the share rising to roughly one-fourth by 2050 as consumers are able to find substitutes for oil in the longer run. Interestingly the consumer burden of the carbon tax on natural gas exceeds the tax. This reflects the sharp rise in demand for natural gas as an initial response to carbon pricing is to substitute gas for coal in electricity generation. By 2050 the producer price is falling for reasonably stringent carbon policies. ${ }^{1}$

Fullerton and Heutel (2007) construct an analytic general equilibrium model to identify the various key parameters and relationships that determine the ultimate burden of a tax on a pollutant. While the model is not sufficiently detailed to provide a realistic assessment of climate change impacts on the U.S. economy it illustrates critical parameters and relationships that drive burden results. The general equilibrium models discussed above all assume a representative agent in the U.S. thereby limiting their usefulness to considering distributional questions. Metcalf et al. (2008) apply results from a representative agent model to data on U.S. households that allows them to draw conclusions about distributional impacts of policies but the household heterogeneity is not built into the model.

Rausch et al. (2010b) does an explicit CGE analysis of carbon pricing in a single-period CGE model. That analysis considers a variety of possible allocations of the revenue and/or allowances from cap-and-trade system and finds that the use of revenues affects the overall progressivity of the policy substantially. It also finds that a significant portion of the carbon price is passed back to factors of production - most notably owners of natural resources and capital. This contributes to a

\footnotetext{
1 Any shift from coal or oil to natural gas in the near term would blunt the sources-side impacts to the extent that capital returns in the gas industry rise. This gives rise to capital inflows to equilibrate capital returns across sectors.
} 
greater progressivity of carbon pricing than found in literature that assumes full forward shifting. This paper builds on that earlier analysis but with considerably more households.

\section{ANALYTICAL FRAMEWORK}

This section provides an overview of the simulation model, and describes the CEX data set and the computational technique employed to integrate endogenously all households as individual agents into the general equilibrium framework.

\subsection{Model Overview}

We employ a static large-open economy version of the MIT U.S. Regional Energy Policy (USREP) model (Rausch et al., 2010a, 2010b), a multi-region and multi-sector general equilibrium model for the U.S. economy. USREP is designed to assess the impacts of energy and climate policies on regions, sectors and industries, and different household income classes. In this paper we extend the earlier model that featured a representative agent for each income class to a model with 15,588 households integrated into a single model. As a detailed algebraic description of the model is provided in Rausch et al. (2010b), we here briefly provide an overview of the model and focus on the key features that are necessary to generalize the model to 15,588 households.

The structure of the model is summarized in Table 1. Much of the sectoral detail in the USREP model is focused on providing an accurate representation of energy production and use as it may change under policies that would limit greenhouse gas emissions. Here we group economic sectors as either energy demand sectors or energy supply and conversion sectors. Energy demand sectors include five industrial and three final demand sectors. Each industrial sector interacts with the rest of the economy through an input-output structure. The model describes production and consumption activities as nested constant-elasticity-of-substitution (CES) production functions. A schematic overview of the nesting structure for each sector is provided in the Appendix A in Rausch et al. (2010b), and is largely similar to the approach implemented in the EPPA model (Paltsev et al., 2005). The energy sector, which emits several of the non- $\mathrm{CO} 2$ gases as well as $\mathrm{CO} 2$, is modeled in more detail. In this analysis we apply a relatively low carbon price, $\$ 20$ per ton $\mathrm{CO} 2$-equivalent with the intent of showing results relevant to the first few years of a climate policy. The static version of the model incorporates electricity generation from fossil fuel, nuclear and hydro power and existing fuels, but not the array of advanced energy supply technologies as in the dynamic version of the model (Rausch et al., 2010a). Electricity outputs generated from different technologies are assumed to be perfect substitutes. We constrain the expansion of nuclear and hydro power to no more than a 20 percent relative to the benchmark level, or given this structure, production from these sources can expand without bound. Other advanced technologies would only be relevant at higher $\mathrm{CO} 2$ prices and further into the future, and so we believe the static model, as formulated, is appropriate to study the effects of a relatively modest GHG pricing policy implemented in the near term.

Hence, results of the USREP show the impact we would expect of implementing a $\mathrm{CO} 2$ price 
Table 1. USREP Model Details.

\begin{tabular}{llc}
\hline Sectors & Regions $^{a}$ & Production Factors \\
\hline Industrial sectors & West (WEST) & Capital \\
Agriculture (AGR) & Mountain (MOUNT) & Labor \\
Services (SRV) & North Central (NCENT) & Resource factors \\
Energy-intensive products (EIS) & South Central (SCENT) & Coal \\
Other industries products (OTH) & South East (SEAST) & Natural gas \\
Transportation (TRN) & North East (NEAST) & Crude oil \\
Final demand sectors & & Hydro \\
Household demand & & Nuclear \\
Government demand & & Land \\
Investment demand & & \\
Energy supply and conversion & & \\
Fuels production & & \\
Coal (COL) & & \\
Natural gas (GAS) & & \\
Crude oil (CRU) & & \\
Refined oil (OIL) & & \\
Electric generation, transmission & & \\
and distribution & & \\
\hline
\end{tabular}

Note: Model regions are aggregations of the following U.S. states: WEST = Alaska, California, Oregon, Washington, Hawaii; MOUNT = Montana, Idaho, Wyoming, Nevada, Utah, Colorado, Arizona, New Mexico; NCENT = Missouri, North Dakota, South Dakota, Nebraska, Kansas, Minnesota, Iowa; SCENT = Oklahoma, Arkansas, Louisiana, Texas; SEAST = Virginia, Kentucky, North Carolina, Tennessee, South Carolina, Georgia, Alabama, Mississippi, Florida; NEAST = Maine, New Hampshire, Vermont, Massachusetts, Connecticut, Rhode Island, West Virginia, Delaware, Maryland, Wisconsin, Illinois, Michigan, Indiana, Ohio, Pennsylvania, New Jersey, District of Columbia, New York.

of \$20 (and maintaining it) over a five to ten year interval. ${ }^{2}$ Like the EPPA model, the USREP model does not measure damages from climate change (or climate benefits from reduced emissions). This model is best suited for carrying out cost effectiveness analyses of proposed emission reductions.

The model distinguishes six regions which are aggregations of U.S. states as defined in Table 1 and visualized in Figure 1. We assume that all goods are tradable. Depending on the type of commodity, we distinguish three different representations of intra-national regional trade. First, bilateral flows for all non-energy goods are represented as Armington (1969) goods where like goods from other regions are imperfectly substitutable for domestically produced goods. Second, domestically traded energy goods, except for electricity, are assumed to be homogeneous

2 Trying to pin down the time dimensions of a general equilibrium model is always risky. Our point here is not so much that this is the relevant time horizon but rather that we are focusing on the response to a modest carbon price that precludes the introduction of highly innovative - and necessarily - speculative technologies that are not yet in existence. 


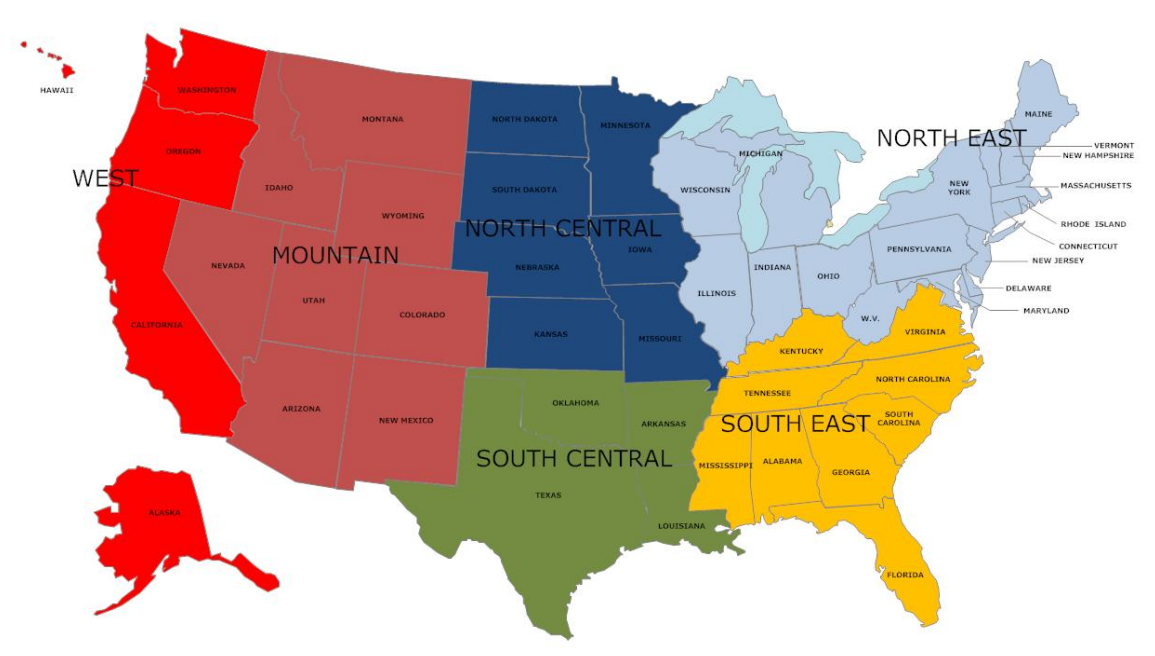

Figure 1. Regional Aggregation.

products, i.e. there is a national pool that demands domestic exports and supplies domestic imports. This assumption reflects the high degree of integration of intra-U.S. markets for natural gas, crude and refined oil, and coal. Third, we differentiate three regional electricity pools that are designed to provide an approximation of the existing structure of independent system operators (ISO) and the three major NERC interconnections in the U.S. More specifically, we distinguish the Western, Texas ERCOT and the Eastern NERC interconnections as separate regional pools. We assume that within each regional pool traded electricity is a homogenous good and that there is no electricity trade between regional pools. ${ }^{3}$

Analogously to the export side, we adopt the Armington (1969) assumption of product heterogeneity for imports. A CES function characterizes the trade-off between imported (from national and international sources) and locally produced varieties of the same goods. Foreign closure of the model is determined through a national balance-of-payments (BOP) constraint. Hence, the total value of U.S. exports equals the total value of U.S. imports accounting for an initial BOP deficit given by the base year statistics. The BOP constraint thereby determines the real exchange rate which indicates the (endogenous) value of the domestic currency vis--vis the foreign currency. The U.S. economy as a whole is modeled as a large open economy, by specifying elasticities for world export demand and world import supply functions. Thus, while we do not explicitly model other regions, the simulations include terms of trade and competitiveness effects of policies that approximate results we would get with a full global model.

We assume that labor is fully mobile across industries in a given region but is immobile across

\footnotetext{
${ }^{3}$ The regional electricity pools are thus defined as follows. The Western NERC interconnection comprises WEST and MOUNT. The Eastern NERC interconnection comprises NEAST, SEAST, and NCENT. Texas ERCOT comprises the SCENT region.
} 
U.S. regions. Capital is mobile across regions and industries. We assume an integrated U.S. market for fossil fuel resources and assume that the regional ownership of resources is distributed in proportion to capital income. ${ }^{4}$

Conventional tax rates are differentiated by region and sector and include both federal and state taxes comprising ad-valorem output taxes, corporate capital income taxes, and personal income taxes. Revenue from these taxes is assumed to be spent in each region, proportional to its current levels. This takes account of varying state tax levels, and the current distribution of the spending of Federal tax revenue among the states. Different assumptions are reasonable but the intent here is to keep a focus on the implications of $\mathrm{CO} 2$ pricing and carbon revenue distribution, and not muddy that by assuming changes in distribution of other Federal or State tax revenues.

\subsection{Data}

Our dataset has three main components: (i) a sample of U.S. households from the 2006 Consumer and Expenditure Survey (CEX), (ii) Social Accounting Matrix data for each U.S. state from the 2006 IMPLAN dataset, and (iii) physical energy and price data from the 2006 State Energy Data System (SEDS) as published by the Energy Information Administration (EIA). By merging these three types of information, we obtain an unusually rich dataset that integrates economic and energy data, captures the heterogeneity of households with respect to spending patterns and income sources, and incorporates information on a number of demographic variables for each household.

\subsubsection{The CEX Sample}

We use the 2006 Consumer Expenditure Survey, a widely used source of data on consumption expenditures, income, and demographic household characteristics (see, e.g., Attanasio, 1998, Fernandez-Villaverde and Krueger, 2006, and Metcalf et al., 2010) that is collected for the Bureau of Labor Statistics. The CEX is a rotating panel, and it is designed to constitute a representative sample of the U.S. population. Each household is interviewed every three months over five calendar quarters, and every quarter 20 percent of the sample is replaced by new households. For the purpose of this paper, there are a number of issues with the way the CEX data are collected that make it difficult to use them directly.

First, we want to include all households that report expenditures and income for 2006 even if they have only been interviewed for a subset of quarters in this year. We follow the procedure outline in Bureau of Labor Statistics (2006, pp. 271) to obtain annual estimates for each household.

Second, the CEX consists of two surveys, the Interview Survey and the Diary Survey. The Interview Survey is designed to capture large purchases, such as spending on rent property and vehicles and those that occur on a regular basis such as rent or utilities. The Diary Survey is

\footnotetext{
${ }^{4}$ Given the lack of data describing the regional ownership of fossil fuel resources in the U.S., we use capital income as a proxy.
} 
meant to capture small frequently purchased items. The Interview Survey collects data on about 95 percent of total household expenditures. We combine data from both surveys to provide a complete account of expenditures by first computing population-weighted averages for each CEX expenditure category for different sub-groups of households in the Diary Survey. We define the sub-groups by income class, region, age, and urban/rural. Based on these sub-groups, we combine sub-group average expenditures from the Diary Survey with expenditures for each household in the Interview Survey. For some expenditure categories data is collected in both surveys; we follow the approach outlined in Bureau of Labor Statistics (2006) to determine which expenditure data is taken from which survey. For our economic model we only use households from the Interview Survey with combined expenditures from both surveys as individual households from the Diary Survey lack data for most of the spending categories.

Third, to obtain expenditure data that are consistent with the definition of consumption goods in our macroeconomic data, we have to map CEX expenditure categories to North American Industry Classification System (NAICS) accounts. This is accomplished by first aggregating CEX data into roughly 70 Personal Consumption Expenditure (PCE) categories, and then using a bridge matrix from the Bureau of Economic Analysis (2007) to map expenditures from PCE to NAICS categories.

Fourth, for about $14 \%$ of households in the CEX data state identifiers have been suppressed for privacy reasons. This occurs mostly in rural states. There is information in the CEX data on which state codes have been suppressed. To retain the representativeness of the sample we keep those households in the data set by randomly assigning them to one of the states with suppressed state identifiers. Fifth, households with income above a certain level are "top-coded", i.e. their income is replaced with the national average. There are different thresholds for different types of income (e.g., \$150k for wage and salary income). At the household level, we see a substantial amount of top-coding for the top $4 \%$ of the income distribution when pre-tax income reaches $\$ 250 \mathrm{k}$. Note that top-coding can make income go both up and down because the replacement value may be higher than the real value. While we keep those households in the sample, this means that we cannot break out the top $4 \%$ income class.

Sixth, a well-known issue with household survey data in general and with the CEX data in particular is that capital income seems to be too low when compared to capital income based on National Account data (e.g., Deaton, 2003, and Rutherford and Tarr, 2008). A second problem with using CEX reported capital income is that it may misrepresent capital holdings across income groups (Metcalf et al., 2010). There are two possible reasons. First, the CEX focuses primarily on spending and the income data quality may not be as high quality as the spending data. Second, if holdings of growth stocks are disproportionately held by higher income groups then the CEX capital income measure will be biased towards more capital holdings in lower income groups. Following Metcalf et al. (2010) we correct for this bias by incorporating data on 
capital income shares by income decile from the 2007 Survey of Consumer Finances (SCF). ${ }^{5}$ More specifically, we replace CEX reported capital income for each household by imputed capital income based on capital income shares by income decile from SCF and total household income from CEX. To accommodate changes in capital income while keeping CEX reported total income fixed at the household level, we adjust labor income.

Seventh, as imputed personal income tax rates using CEX reported income tax payments are too low, we incorporate personal income tax rates based on data from the NBER TAXSIM tax simulator. A final issue with the use of the CEX data is that for the purpose of including households in the general equilibrium model, we need to ensure that income balance is satisfied in the benchmark equilibrium. This condition requires that pre-tax household income is equal to the sum of consumption expenditures, tax payments, and savings. As savings are not reported directly in the CEX data, we impute savings as pre-tax household income minus the sum of consumption expenditures and tax payments, and use this approach to close the income balance. For about $35 \%$ of households in the sample, consumption expenditures exceed total household income, i.e. there is not sufficient current income to finance observed consumption. As there does not seem to be a perceivable pattern in the CEX data that would help to identify the type of income that falls short of observed expenditures, we assume for these households that consumption in excess of observable household income is financed by a stream of capital income. ${ }^{6}$

\subsubsection{National Account and Energy Data}

Our model is based on state-level data from IMPLAN (Minnesota IMPLAN Group, 2008) in the form of Social Accounting Matrix (SAM) data covering economic transactions among businesses, households, and government agents for the year 2006. Aggregation and reconciliation of IMPLAN state-level economic accounts to generate a benchmark data set which can be used for model calibration is accomplished using ancillary tools documented in Rausch and Rutherford (2009). In addition, our data set integrates energy data from the Energy Information Administration's (EIA) State Energy Data System (Energy Information Administration, 2009) comprising price and quantity data on energy production, consumption and trade. For each state, we have replaced all energy data in the economic IMPLAN data set with assembled price-quantity EIA data and used optimization techniques (ordinary least squares) to reconcile economic and energy data Rausch and Rutherford (2009). The integrated data set is

\footnotetext{
${ }^{5}$ One advantage of using the SCF is that it disproportionately samples wealthy families. Each survey consists of a core representative sample combined with a high income supplement, which is drawn from the Internal Revenue Service's Statistics of Income data file. Further, the survey questionnaire consists of detailed questions on different components of family wealth holdings. For these reasons, the SCF is widely acknowledged to be the best at capturing both the wealth at the top of the distribution and the complete wealth portfolio of households in the middle. Since the wealth distribution is highly skewed towards the top, most other surveys (like the CEX) that have poor data on high income families tend to underreport measures of income and wealth.

${ }^{6}$ Future work has to explore the implications of different assumptions for reconciling the income and expenditure accounts of individual households.
} 
micro-consistent and is benchmarked to EIA energy statistics. Additional data for the greenhouse gas $\left(\mathrm{CO}_{2}, \mathrm{CH}_{4}, \mathrm{~N}_{2} \mathrm{O}\right.$, HFCs, PFCs and $\left.\mathrm{SF}_{6}\right)$ emissions is based on U.S. Environmental Protection Agency (2009) inventory data, including endogenous costing of the abatement of non- $\mathrm{CO}_{2}$ greenhouse gases (Hyman et al., 2002). Following the approach outlined in Paltsev et al. (2005) the model incorporates supplemental physical accounts to link economic data in value terms with physical quantities on energy production, consumption and trade.

\subsection{Computational Approach and Reconciliation of National Account and Household Sur- vey Data}

The main challenge for computing equilibria in a numerical model with 15,588 households is dimensionality. Simultaneous solution methods that operate directly on the system of equations that define the general equilibrium (GE) can become infeasible if the number of variables and equations is too large. We use a decomposition algorithm by Rutherford and Tarr (2008) and Rausch and Rutherford (2010) to integrate all households endogenously within our general equilibrium model.

The key idea of the algorithm is to solve a market economy with many households through the computation of equilibria for a sequence of representative agent (RA) economies. The algorithm decomposes the numerical problem into two sub-problems and employs an iterative procedure between them to find the equilibrium of the underlying model. The first sub-problem computes candidate equilibrium prices from a version of the GE model where the household demand side in each region is replaced by a single RA. The second sub-problem solves a partial equilibrium (PE) relaxation of the underlying model by evaluating demand functions for each of the 15,588 households given candidate GE prices from the RA problem. The iterative procedure between both sub-problems involves the re-calibration of preferences of the RA in each region based on PE quantity choices by "real" households. This ensures that the GE prices derived from the RA model, which include a mutually consistent GE response of firms and the demand by the RA, are consistent with PE demand by individual households. The algorithm finds the equilibrium of the underlying economy if the sequence of GE prices and PE quantities converge to the true equilibrium prices and quantities. ${ }^{7}$ Appendix A describes our specification of household utility and the implementation of the decomposition algorithm in the context of the USREP model.

In order to implement our integrated model and to apply the decomposition algorithm we have to produce a balanced Social Accounting Matrix that reconciles differences between aggregated consumption, factor and resource incomes, and transfers from National Account IMPLAN data and household survey CEX data. This step is necessary to ensure that in the absence of a policy

\footnotetext{
${ }^{7}$ Rutherford and Tarr (2008) use this technique to solve a large-scale, static general equilibrium model with 25 sectors and 53,000 households to assess the poverty effects of Russia's WTO accession. Rausch (2009) and Rausch and Rutherford (2010) apply a variant of the method to compute equilibria in multi-sector multi-region overlapping generations models with many heterogeneous households to study the macroeconomic implications of demographic change.
} 
Table 2. Carbon Revenue Distribution Scenarios.

\begin{tabular}{ll}
\hline Scenario & Description \\
\hline inctax & Marginal income tax rates for all households are reduced by the same percentage amount. \\
percapita & Equal per capita lump sum transfers to households. \\
capital & Lump sum transfers to households proportional to capital income.
\end{tabular}

Note: In all scenarios, government spending is held fixed at its benchmark level. Revenue neutrality is achieved by endogenously calculating the reduction in income tax rates or by withholding a fraction of the carbon revenue, respectively.

shock iterating between the RA GE and the PE household modules returns the no-policy benchmark equilibrium. Violation of this initial condition would mean that simulated policy impacts are confounded with equilibrium adjustments due to initial inconsistencies between the benchmark of the two sub-models.

We produce a balanced SAM by introducing an artificial household in each region where benchmark consumption by commodity and income by source are calculated as residuals between National Accounts and the (aggregated) CEX data. The virtue of this approach is to preserve both the macroeconomic description of the economy and the individual household data. One caveat of this approach is that estimates for economy-wide welfare costs have to take into account welfare changes by the artificial households, i.e. they have to be based on the entire economy. ${ }^{8}$

\subsection{Calibration}

As is customary in applied general equilibrium analysis, we use prices and quantities of the integrated economic-energy data set for the benchmark year 2006 to calibrate the distribution parameters of the CES functions that describe production and consumption technologies. Exogenous elasticities determine the free parameters of the functional forms, and Tables A1-A2 in Rausch et al. (2010b) provide a full list of the numerical values used to parameterize the model.

\section{SCENARIOS AND ANALYSIS}

\subsection{Model Scenarios}

We now consider a climate policy with an equilibrium carbon price of $\$ 20$ per ton of carbon dioxide-equivalent $\left(\mathrm{CO}_{2} \mathrm{e}\right)$. This could be implemented either through a cap and trade system or a carbon tax. In our model, the two approaches are indistinguishable. A cap and trade system with fully auctioned permits is equivalent in impact to a carbon tax where the tax rate equals the market clearing auction price. As noted above, distributional impacts of carbon pricing depend in part on the use of proceeds raised by the policy. We consider three revenue distribution schemes as described in Table 2.

\footnotetext{
${ }^{8}$ We note that other approaches to data reconciliation are conceivable that do not rely on the introduction of an artificial household. Such approaches would either adjust the national account data or the household survey data (or a combination of both) depending on how much weight is placed on each data set. Future work has to explore the sensitivity of model results with respect to different approaches to reconcile both data sources.
} 
In the first scenario (inctax), revenue from auctioning of permits is used to lower marginal tax rates on income. Marginal rates are reduced endogenously by 5.64 percent. This should provide efficiency benefits as discussed in the large literature on the Double Dividend (see Goulder, 1995, for a description of this literature). The second scenario (percapita) distributes the revenue to households on an equal per capita basis. Thus a household of four would receive a transfer twice as large as a household of size two. It is expected that this allowance allocation will have a more progressive distributional outcome but at the cost of efficiency. The third scenario (capital) distributes revenue to households in proportion to their capital income. If permits are freely allocated to carbon intensive industries, as they have been in the EU Emissions Trading Scheme, they provide a lump sum windfall to owners of this industry. We model this by assuming that the distribution of ownership in carbon intensive industries matches the distribution of capital ownership in general. ${ }^{9}$

For all scenarios we impose revenue neutrality by holding government spending-including transfer payments-fixed at its benchmark level. ${ }^{10}$ For scenarios where we use lump-sum recycling instruments, we assume that an endogenously determined fraction of the carbon revenue is withheld to satisfy the neutrality constraint. In the inctax scenario we solve endogenously for a uniform percentage reduction in marginal income tax rates. ${ }^{11}$

\subsection{Results}

We begin by reporting average welfare impacts of a cap and trade system with a $\$ 20$ per ton $\mathrm{CO} 2 \mathrm{e}$ permit price. Welfare impacts are measured as the equivalent variation (EV) of the policy reported as a percentage of household income. Average costs are lowest if the carbon revenue is used to lower personal income tax rates ( 0.18 percent of household income). Consistent with the Double Dividend literature, welfare costs rise if the revenue is returned lump sum. The costs in this case are over twice as great ( 0.38 percent for the capital and 0.46 percent for the percapita scenario). Welfare costs are higher if the revenue is returned on a per capita basis than proportional to capital income. The result that changes in the lump sum distribution scheme can have efficiency consequences has also been found by Rausch et al. (2010a). Increasing the share of allowance value to high income households relative to low income households lowers the cost of the policy as high income households spend a smaller fraction of any distribution on carbon intensive products.

Figure 2 shows the distributional impact by annual income groups for the various scenarios.

\footnotetext{
${ }^{9}$ We have not made an adjustment for capital income received by foreigners. This affects the analysis to some extent by allocating to US capital owners a portion of the burden that falls outside the United States. This should not appreciably affect the results.

${ }^{10} \mathrm{In}$ a static model, this is equivalent to indexing transfer payments since the price level is the numeraire price.

${ }^{11}$ Assuming separability between utility derived from private and government spending, the revenue neutrality constraint allows us to compare welfare impacts across different scenarios by holding the utility of government spending constant.
} 


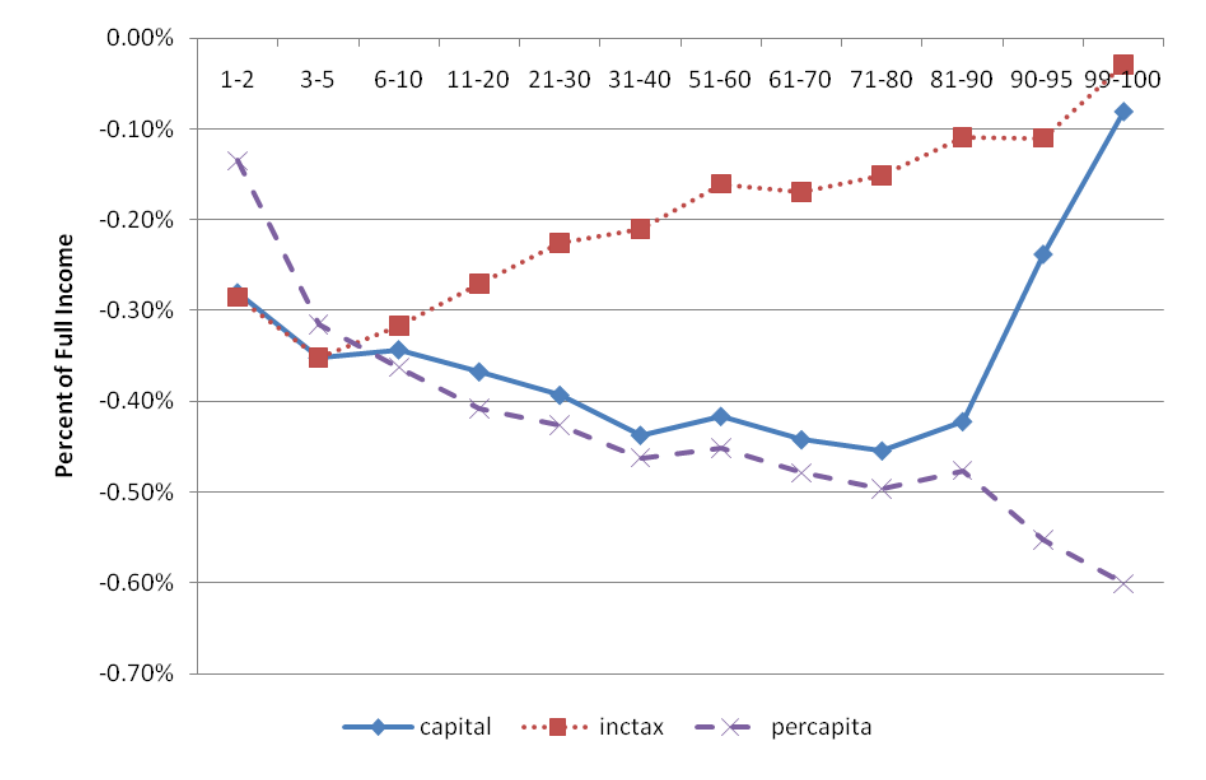

Figure 2. Average Welfare Impacts by Income Group.

We report averages for income deciles except for the top and bottom deciles, where we show results for finer disaggregations. At the bottom of the distribution, we are concerned the very high consumption to income ratios reported in the Consumer Expenditure Survey mask significant income underreporting along with borrowing among certain household groups (most notably young and old households). Focusing first in the inctax scenario and setting aside the bottom two percent of the income distribution, the carbon price with income tax reductions is regressive with burdens ranging from -0.3 percent in the lowest decile to -0.1 percent in the top decile. This is consistent with other analyses and reflects the tension between equity and efficiency in policy setting.

The two forms of lump-sum redistribution both show higher average costs but very different relative costs across the income distribution. Per capita household rebates are progressive-even if one ignores the bottom two percent of the household income distribution. In contrast, the scenario corresponding to free allocation of permits to carbon intensive industries is proportional over the bottom 90 percent of the income distribution but regressive in the top decile.

As noted above, a number of researchers have argued that energy taxes look more regressive than is in fact the case because of biases that are impacted by the use of annual income to rank households. There are two issues here. First, households are likely to smooth consumption over transitory income shocks. Smoothing will tend to bias measures of consumption taxes toward greater measured regressivity. Second, households making consumption decisions on the basis of lifetime income may also have very high consumption to income ratios in periods when income is low (e.g. at the beginning or end of life).

To address these factors, we show distributional results using two proxies for lifetime income. Our first measure restricts attention to households where the head of household is between the 


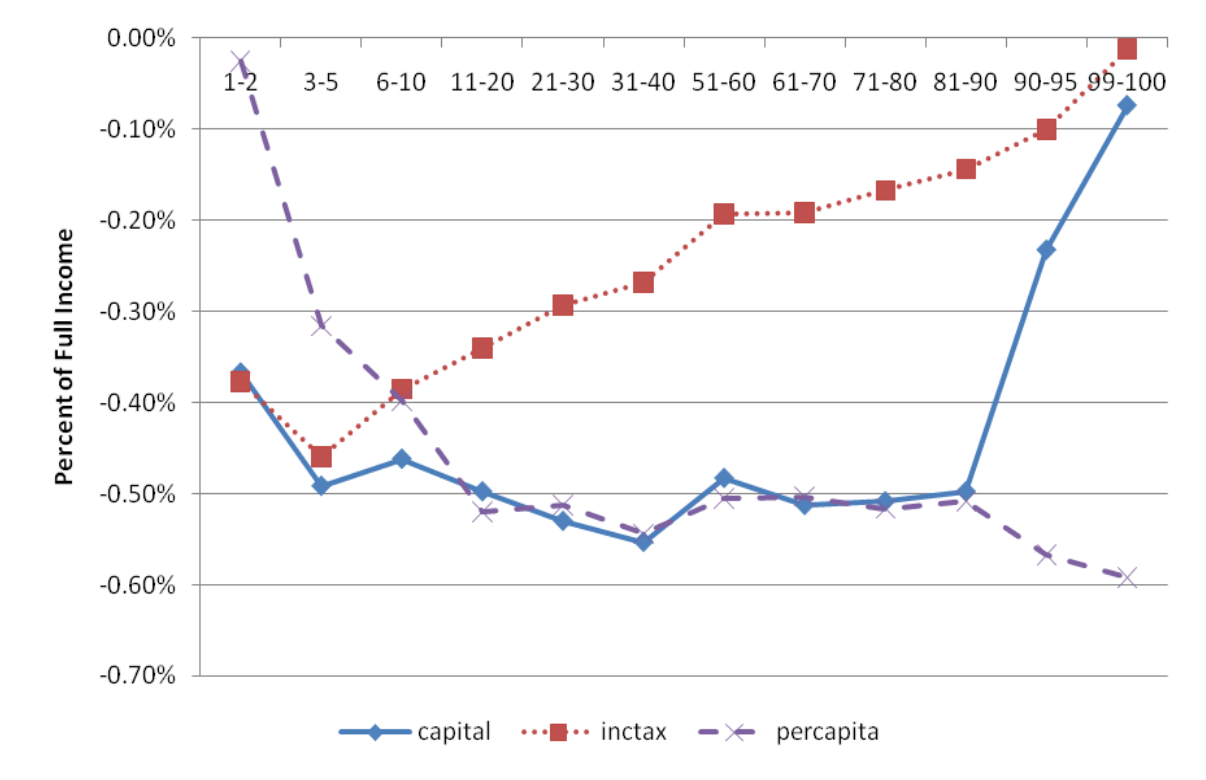

Figure 3. Mean Welfare Impacts by Income Group: Age 40-60.

ages of 40 and 60. This excludes young households who are making consumption decisions in anticipation of higher future income and elderly households who may be drawing down savings in retirement. Results are shown in Figure 3. Excluding the bottom two percent of the income distribution, the inctax and capital scenarios continue to look modestly regressive while the percapita scenario is quite progressive.

As a second proxy for lifetime income we classify households by educational outcome of the head of household (Figure 4). Under the assumption that education is positively correlated with lifetime income, we continue to find the same distributional patterns as we found using annual income to rank households. Based on the results from Figures 3 and 4, it does not appear that significant bias arises from using annual income measures in this analysis.

We also report results where we decompose impacts by racial and ethnic groups (Table 3). The USREP model calibrates the model to reflect factor income and expenditure shares by these groups (as well as by income, education, and region). Households with a Black head bear a higher burden than do households with a White or Other head (the last group includes Native American, Asian, Pacific Islander, and Multi-race). The average burden under the inctax scenario is 191 percent higher for Blacks than Whites. This reflects differences in income and spending patterns across the two groups, not anything inherent to racial characteristics.

Interestingly, the ratio of the Black to White burden is higher for this scenario than for the capital scenario. The percapita distribution reduces the difference to 124 percent. The higher burden on Blacks can mainly be explained by the observed differences in spending patterns according to the CEX data: Blacks exhibit a higher expenditure share of electricity $(4.8 \%)$ and natural gas $(2.0 \%)$ compared to Whites $(2.9 \%$ and $1.1 \%)$, respectively.

Hispanics also appear to incur a higher burden of carbon pricing than do other groups for the 


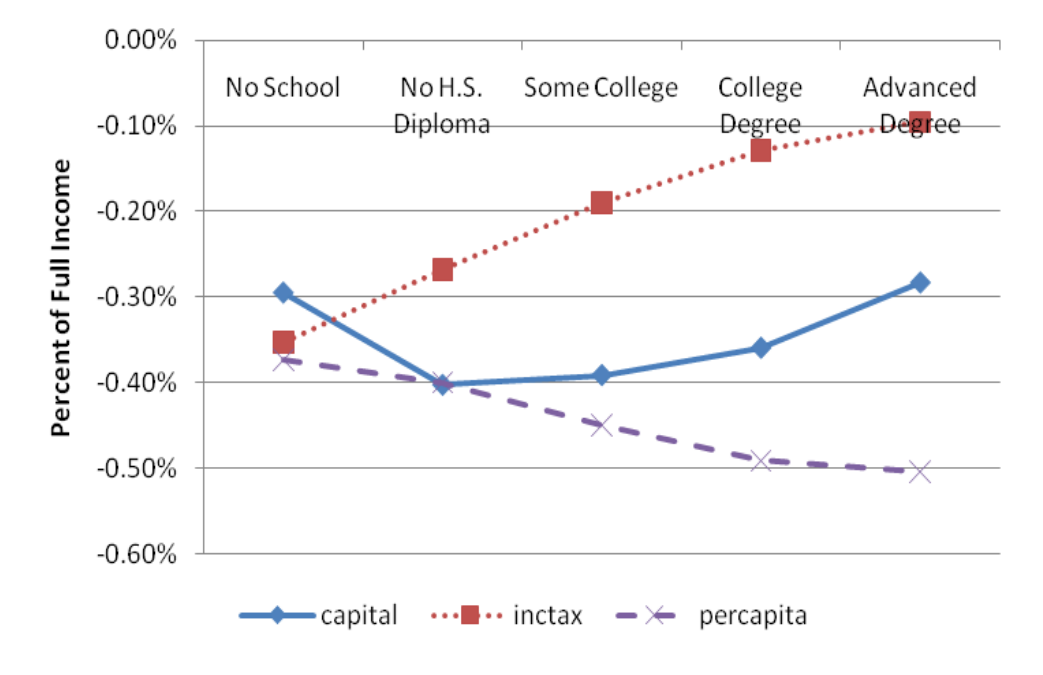

Figure 4. Mean Welfare Impacts by Education.

Table 3. Mean Welfare Change by Race and Ethnic Group.

\begin{tabular}{lccc}
\hline & \multicolumn{2}{c}{ Scenario } \\
\cline { 2 - 4 } & inctax & percapita & capital \\
\hline Race & & & \\
White & -0.17 & -0.37 & -0.45 \\
Black & -0.32 & -0.50 & -0.56 \\
$\quad$ Other & -0.06 & -0.25 & -0.37 \\
Ethnic Group & & & -0.37 \\
$\quad$ Other & -0.17 & -0.46 & -0.42 \\
$\quad$ Hispanic & -0.21 & -0.43 & -0.41 \\
All & -0.19 & -0.41 & \\
\hline
\end{tabular}

capital and inctax scenarios. The discrepancy is not as large as between Blacks and Whites. In fact their average burden is lower under the percapita scenario. We track this difference to the sources side. On average, Hispanics derive a significantly smaller fraction of their annual income from government transfers ( $11.3 \%$ versus $16.8 \%$ for other ethnic groups) which means that are less insulated against adverse factor price changes.

In previous papers (see Rausch et al., 2010a, 2010b) we have shown that carbon pricing policy has differential impacts across regions with the North and South Central parts of the country disproportionately affected. Conversely the North East and West are least impacted. Our analysis here upholds those results (Figure 5). These results reflect the reliance of the middle parts of the country on coal for electricity generation. The North East and West, in contrast, are more reliant on hydro and nuclear power for electricity generation. The mean welfare change in the West is positive under the inctax scenario, as this region exhibits by far the lowest emissions and energy intensity of Gross State Product of all regions translating into relatively modest price increases for electricity and carbon-intensive goods. At the same time household benefits from the uniform reduction in personal income tax rates across regions that is based on the sum of regional carbon 


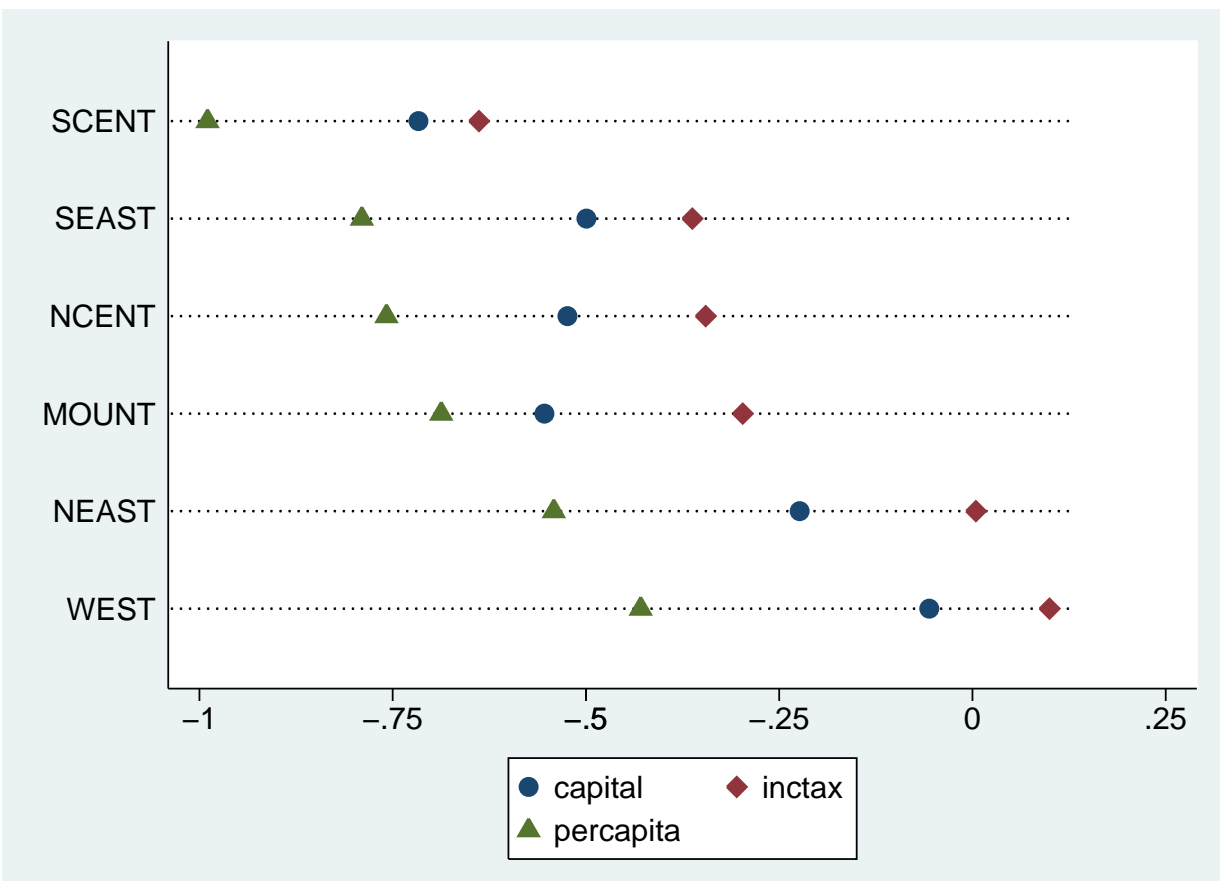

Figure 5. Mean Welfare Impacts by Region.

revenues.

\subsection{Heterogeneity in Impacts}

Tracking a large number of households allows us to explore burden impacts in greater detail. Here we consider the variation in impacts within groups. Consider Figure 6. This shows box plots for burden impacts within annual income deciles for the three scenarios

Consider the Box Plot for the inctax scenario. The inner quartile range (IQR) for burden impacts in the lowest income decile runs from -0.4 to 0.1 percent of income. Over one-quarter of households in this income group benefit from this policy. This is true in all income groups. While the median (and mean) welfare impacts are negative for each group, between one-quarter and one-half of households in each group benefit from this policy. The "whiskers" show outlier values within 1.5 times the IQR of the nearest quartile. For the inctax scenario, the largest negative outlier burdens were roughly one percent of income. Figure 6 makes the point that focusing on averages across income groups obscures important variation within income groups that may swamp the variation in average effects across income groups.

Figure 7 presents additional information on the heterogeneity of impacts by income groups. In particular, it shows the share of households that incur a welfare loss in excess of one percent of annual income. Focusing on the inctax scenario, 11.5 percent of households in the lowest decile incur such a large loss. Interestingly, the share falls as income rises up to the fifth decile where 1.4 percent of households incur a large loss. It stabilizes at this level across the top part of the income distribution.

A larger share of households can experience large welfare losses (in excess of one percent of 

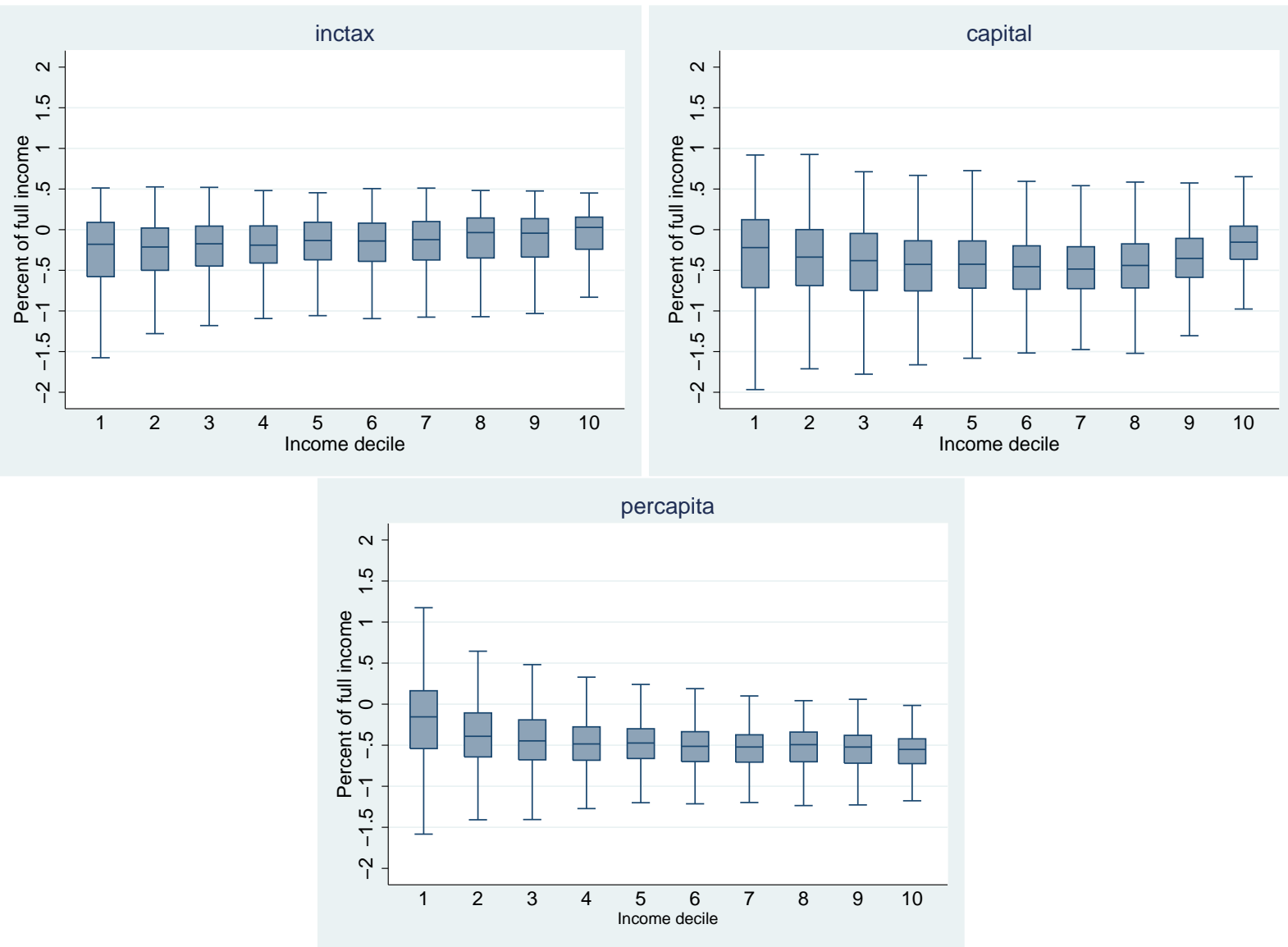

Figure 6. Box Plots by Income Decile.

income) under the capital scenario. As many as 5 percent of households experience these losses through the seventh decile. The percapita scenario has a pattern of large losses similar to the inctax scenario though with significantly larger impacts up to the fifth decile and with rising losses for the top of the distribution.

We repeat this analysis looking at households across regions (Figure 8). As above, a greater percentage of households are likely to suffer large losses in the capital and percapita scenarios than inctax scenario. The South Central region has the largest share under any of the scenarios. The percentage of households in this region who suffer large losses ranges between 17 and 33 percent. Just as the Northeast and West are least adversely impacted by carbon pricing under the various rebate scenarios, these regions are least likely to have households with large losses. The biggest difference across regions is their fuel source for electricity. Figure 9 shows that considerably more electricity is generated by coal in Mountain states and the North Central parts of the country than elsewhere.

A similar pattern emerges for racial and ethnic groups. Households with Black heads are more likely to suffer a large loss with the probability being highest under the capital scenario (Figure 10). A similar pattern emerges for Hispanic groups. 


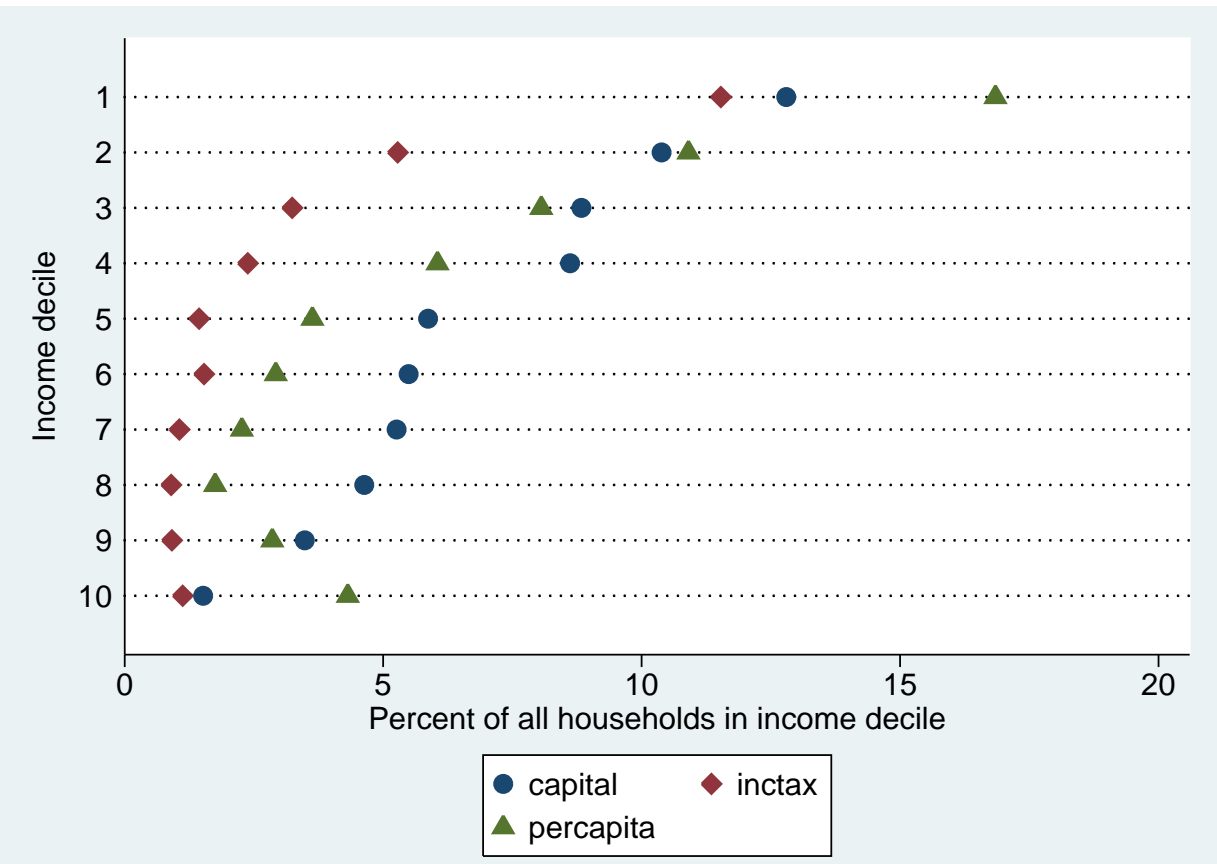

Figure 7. Percent of Households with Welfare Loss in Excess of 1 Percent of Income: by Income.

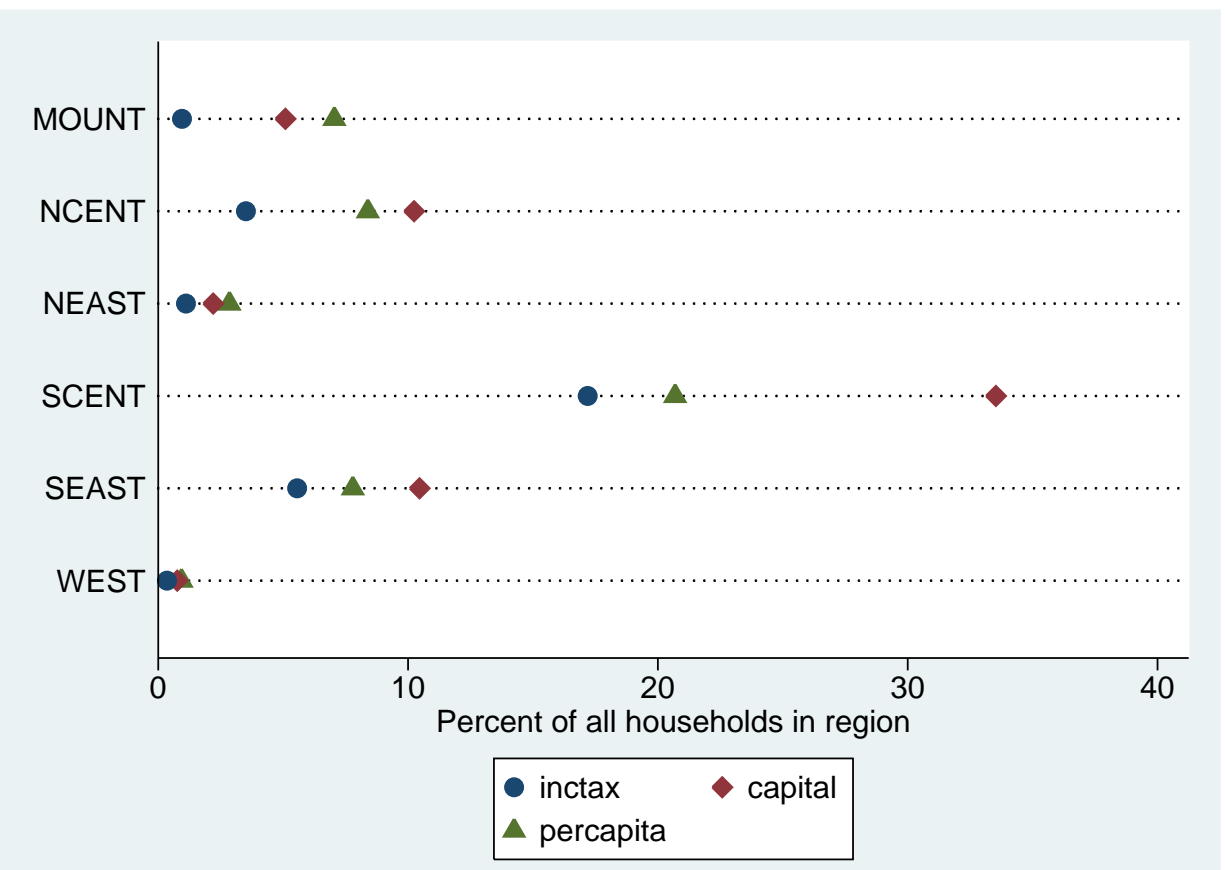

Figure 8. Percent of Households with Welfare Loss in Excess of 1 Percent of Income: by Region.

\subsection{Drivers of Impacts}

Finally, we explore the drivers of the various impacts across the different groups. Impacts can occur on both the sources and uses side. We explore each in turn. 


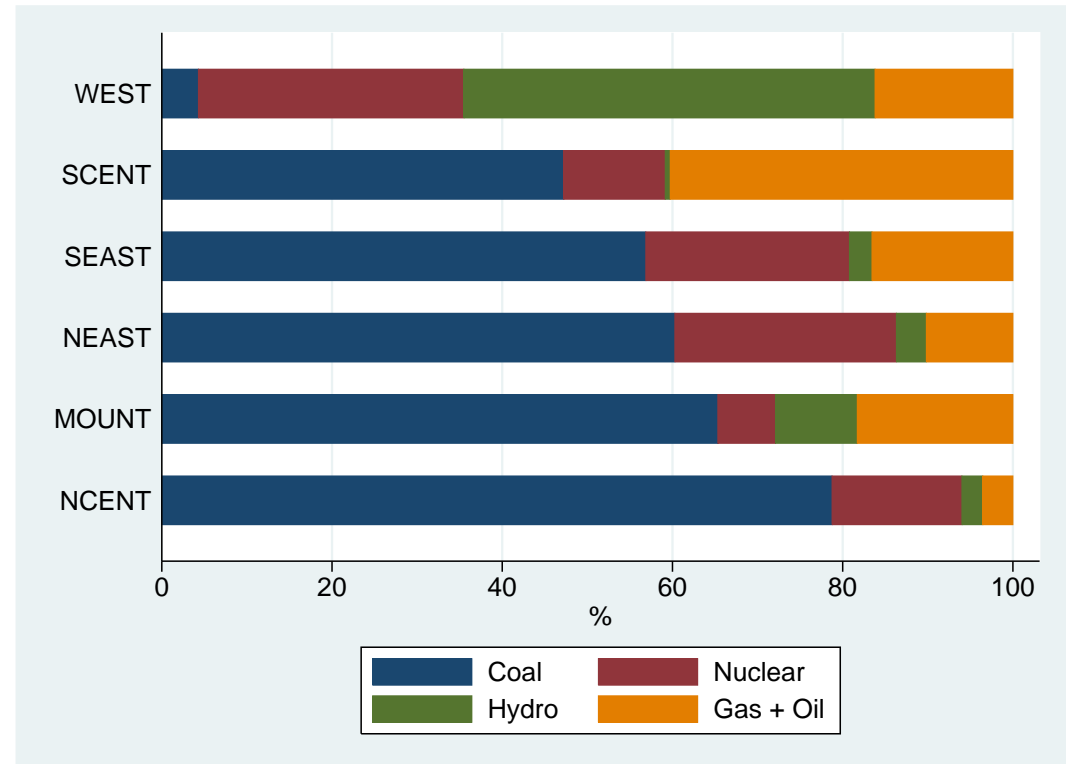

Figure 9. Electricity Generation by Fossil Fuel Across Regions.

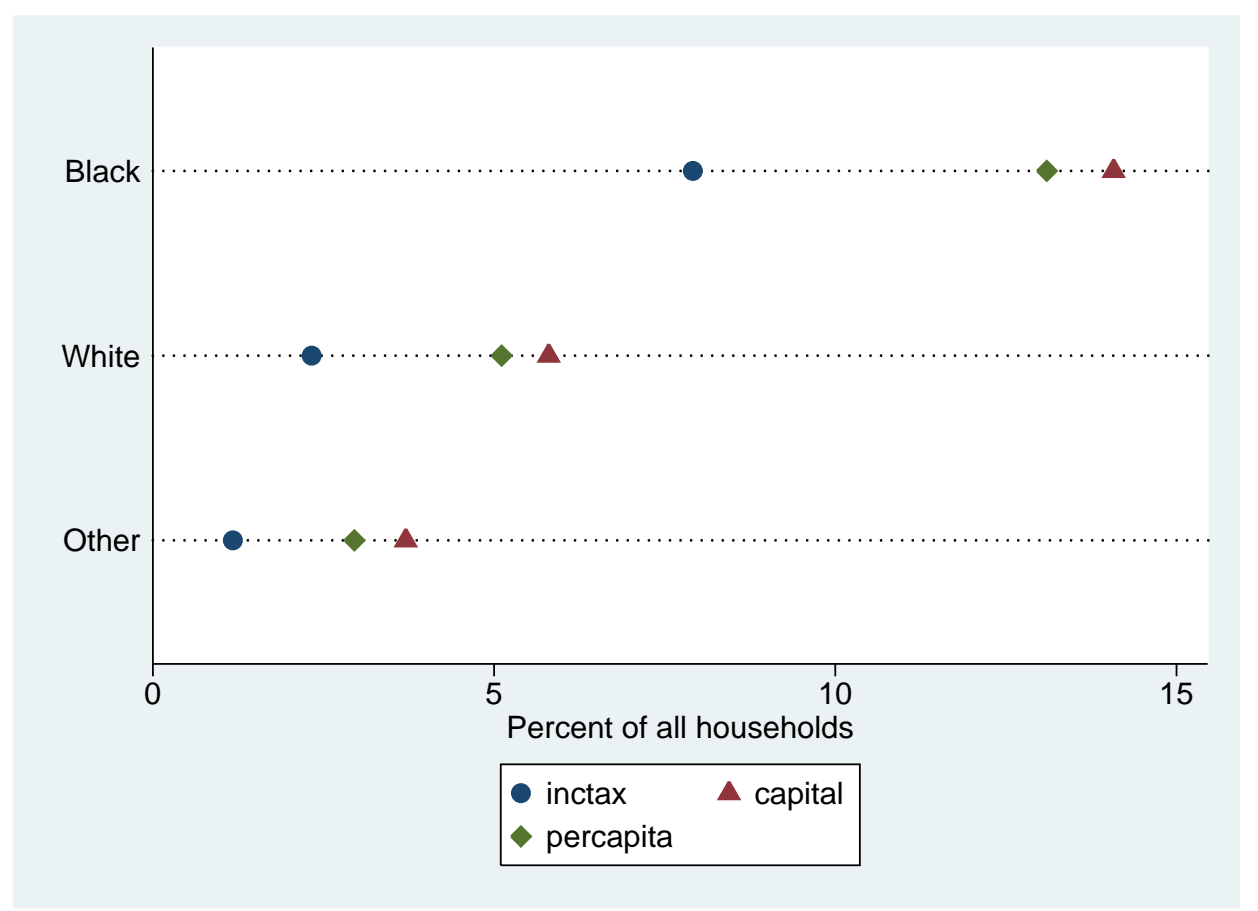

Figure 10. Percent of Households with Welfare Loss in Excess of 1 Percent of Income: by Race.

\subsubsection{Sources of Income}

Carbon policy will affect factor prices in potentially differential ways. Recall that labor is mobile within but not across regions in our model. Therefore carbon policy differentially affects wage rates. Figure 11 reports on the primary axis wage changes across regions under the different scenarios and on the secondary axis regional indices for energy and greenhouse gas emissions 

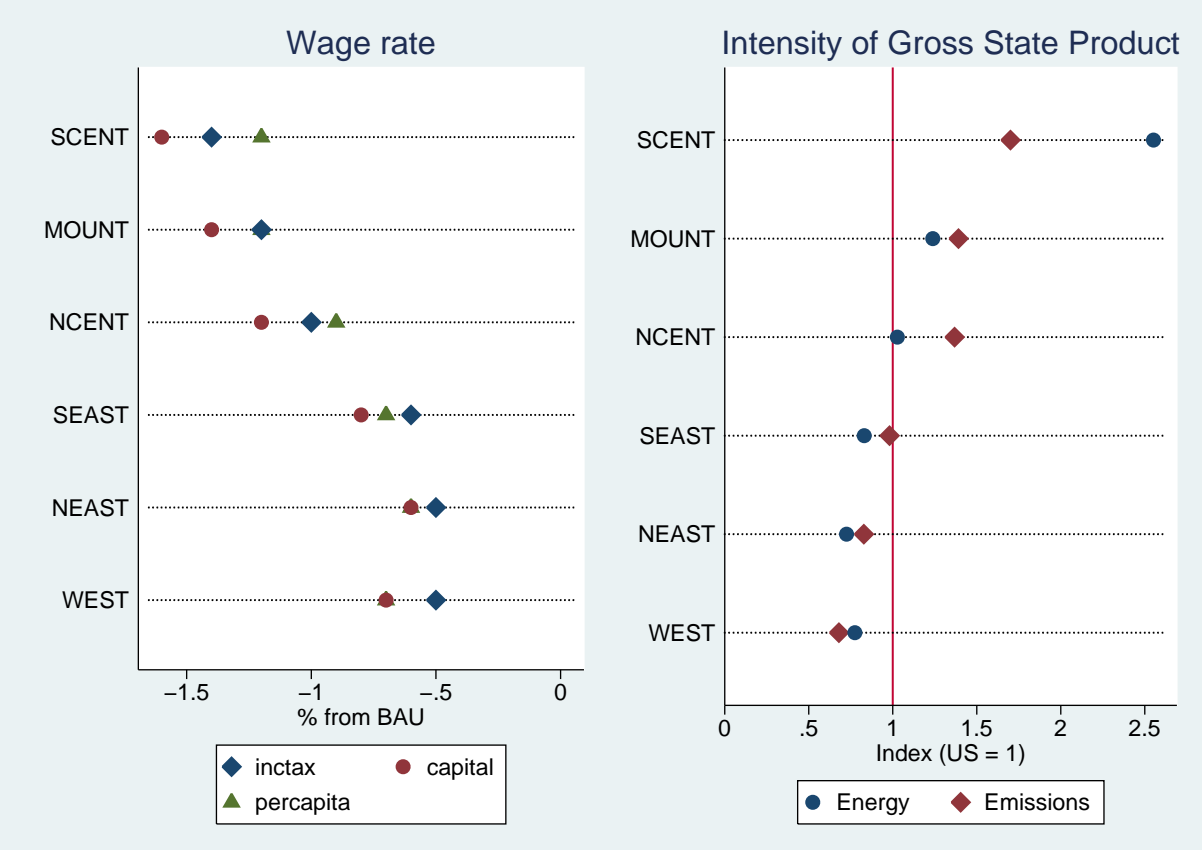

Figure 11. Changes in Wages and Energy and Emissions Intensity.

intensity. The indices measure benchmark energy use (in Exajoules) and emissions (million metric tons) per dollar of Gross State Product, respectively, and are normalized to one for the U.S. A value larger than one means that regional intensity is above the respective U.S. average. Wage rates fall the most in the Mountain states as well as the North and South Central states as the impact on industrial activity and hence labor demand in these regions is relatively large due to high energy and emissions intensities. Conversely, the NEAST and WEST regions that have already de-carbonized to some extent experience only relatively small reductions in wage rates.

Capital, on the other hand, is traded in national markets. The percentage change in after-tax of return capital rental rates for the inctax, capital, and percapita scenarios are -0.9, -1.1, and -1.1, respectively. The rates fall the least in the inctax scenario reflecting the reduction in marginal tax rates on income in this scenario. We compare this with an U.S. average of regional wage changes. The percentage after-tax return of wage rates for the for the inctax, capital, and percapita scenarios are $-0.8,-0.7$, and -0.7 , respectively.

Wages on average fall less than capital rental rates. Figure 12 shows household sources of income by type. The share of income from capital is slightly declining up to the fourth decile and is then roughly constant through the 80th percentile at which point it begins to rise. The share of income from labor rises with income while the importance of government transfers diminishes. This pattern suggests two things. First our treatment of transfer income adds progressivity to carbon pricing. By holding the price of transfer income constant (put differently, holding transfer income constant as part of our treatment of government in the model), lower income groups that depend more heavily on transfer income benefit as factor prices fall. While it is certainly possible that government will adjust transfers as part of a larger adjustment to carbon pricing, it should be 


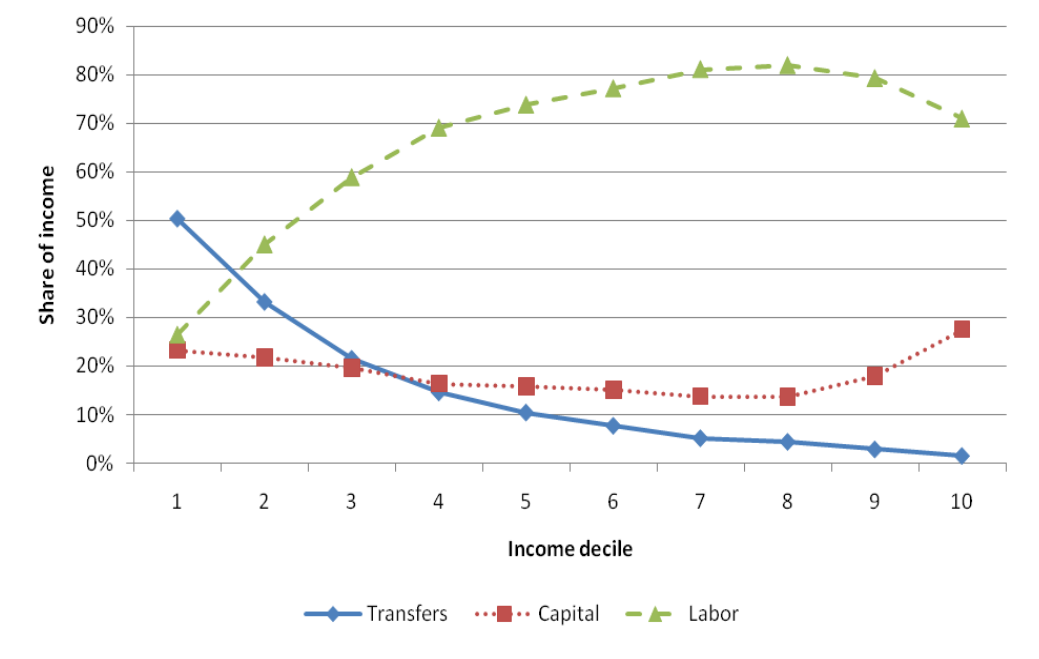

Figure 12. Income Sources.

Table 4. Average Welfare Impact by Combined Expenditure Share for Electricity and Natural Gas (Percent of Full Income).

\begin{tabular}{lrrr}
\hline & \multicolumn{3}{c}{ Scenario } \\
\cline { 2 - 4 } Share & inctax & capital & percapita \\
\hline$<0.1$ & -0.13 & -0.34 & -0.43 \\
$0.1-0.2$ & -0.84 & -1.00 & -0.85 \\
$0.2-0.3$ & -1.26 & -1.38 & -1.20 \\
$0.3-0.4$ & -1.89 & -1.89 & -1.61 \\
$0.4-0.5$ & -2.57 & -2.64 & -2.31 \\
$0.5-0.6$ & -3.14 & -3.12 & -3.11 \\
\hline
\end{tabular}

clear that such an adjustment mixes climate policy with a fiscal policy decision.

Second, higher income households are affected on the sources side due to the larger fall in wage rates than capital rental rates. Capital income constitutes a higher proportion of income for households in the top two deciles. The decline in the capital to labor factor return adversely affects these high income households as a result.

\subsubsection{Uses of Income}

Uses side impacts are driven in large part by expenditures on electricity and natural gas. Table 4 shows that the average welfare change rises sharply for all scenarios with the share of spending on these two commodities.

Turning to income groups, we see that electricity and natural gas are disproportionately important in low-income budgets (Table 5). Similarly Black households show a higher fraction of spending on these two commodities. Residents in the South Central and South East regions consume electricity at higher shares of spending than residents of other regions. As noted above, electricity in the South Central region is more carbon intensive exacerbating the impact of carbon pricing on residents of this region. 
Table 5. Benchmark Expenditure Shares for Electricity and Gas by Income, Race, Ethnic Group, and Region (Percent of Total Expenditures).

\begin{tabular}{lrr}
\hline & Electricity & Natural Gas \\
\hline By Income Decile & & \\
1 & 5.8 & 2.2 \\
2 & 4.5 & 1.8 \\
3 & 3.7 & 1.3 \\
4 & 3.5 & 1.2 \\
5 & 3.0 & 1.1 \\
6 & 3.0 & 1.1 \\
7 & 2.6 & 1.0 \\
8 & 2.3 & 0.9 \\
9 & 2.1 & 0.9 \\
10 & 1.8 & 0.8 \\
By Race & & \\
White & 2.9 & 1.1 \\
Black & 4.8 & 2.0 \\
Other & 2.3 & 0.9 \\
By Ethnic Group & & \\
Hispanic & 3.2 & 1.0 \\
Other & 3.1 & 1.2 \\
By Region & & \\
MOUNT & 1.8 & 1.1 \\
NCENT & 2.4 & 2.0 \\
NEAST & 2.5 & 1.3 \\
SCENT & 5.9 & 1.0 \\
SEAST & 5.1 & 0.9 \\
WEST & 2.4 & 0.9 \\
All & 3.1 & 1.2 \\
\hline
\end{tabular}

\subsubsection{Decomposing Uses and Sources Side Effects}

To better understand the relative importance of sources and uses side impacts, we run one additional simulation where we impose the carbon pricing policy and use the revenue in ways that do not enter the consumers' utility functions. This allows us to isolate the distributional impacts of carbon pricing by itself without respect to the use of revenues. We then consider two counterfactuals. First, we recalibrate the model so that all households have identical expenditures shares for each commodity regardless of income. Any burden differences across income groups will therefore be driven entirely by sources side effects. The second counterfactual is constructed by re-calibrating the model so that all households have identical factor income shares regardless of income. Now all burden differences across income are driven by uses side effects.

Figure 13 shows the carbon pricing burdens as a percentage of full income for carbon pricing itself and the two counterfactuals. The first thing to note is that carbon pricing by itself is roughly proportional. The burden ranges from 0.61 percent of full income for the lowest income decile to 0.67 percent of income for the fourth, sixth, and seventh deciles. The progressivity or regressivity of the various scenarios we analyzed above are entirely driven by the mechanism for distributing proceeds from carbon pricing. 


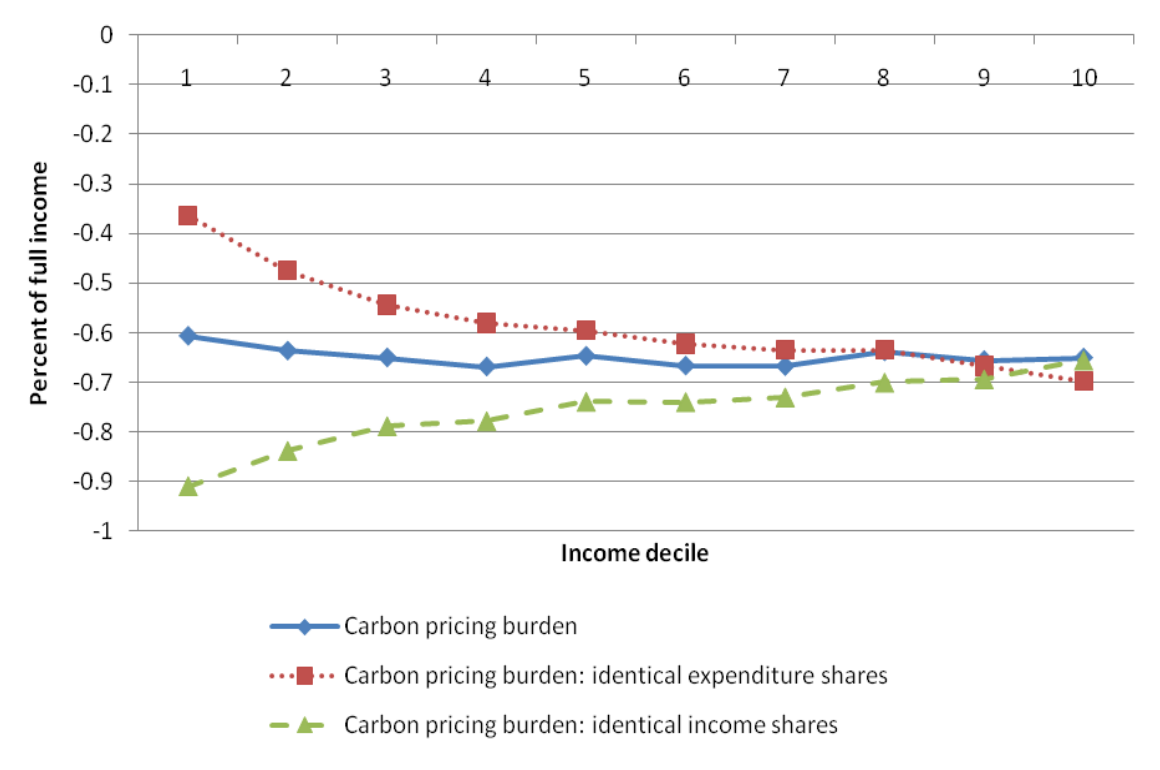

Figure 13. Relative Sources vs. Uses Side Impacts across Income Distribution.

The second finding from the counterfactual analyses is that the burden of carbon pricing (by deciles) arising from uses side effects is regressive. The average burden by deciles ranges from 0.91 percent of income for the lowest income group to 0.65 percent for the highest income group. ${ }^{12}$ This finding is consistent with the various partial equilibrium uses side studies discussed in section 2.

Finally, the average burden of carbon pricing arising from sources side effects is progressive. Now the burden ranges from 0.36 percent of income for the lowest decile to 0.70 percent for the highest income groups. The sources side progressivity is sufficiently strong to completely offset the uses side regressivity.

What drives this surprising result? First, rental returns fall relative to wages. Since capital income is a particularly large share of income for high income households, the relative factor income shares disproportionately impact high income households. It should be noted that this model is a closed economy model. If carbon pricing were introduced in the United States in the context of an open economy, the capital income effects would no doubt be moderated. But leakage would also affect results on both the sources and uses side so one cannot predict the distributional results. If carbon pricing were introduced, however, globally, then the results are likely to still go through since capital cannot shift to economies that do not price carbon.

The second force at work driving this progressivity result is the fixing of transfer income in real terms. Transfer income is a particularly large share of income for low income households so

12 Note that all households are adversely affected since the carbon revenue is spent in ways that do not enter consumer utility functions. 
this assumption is an important driver of our result. How government will in fact adjust transfer payments if carbon pricing were introduced cannot be predicted. Fullerton et al. (2011) find that over 90 percent of transfer payments in the United States are explicitly indexed thereby providing support for the approach we took in this paper.

\section{CONCLUSION}

This paper makes five key points. First, how proceeds of a carbon pricing policy are used affects both the efficiency and equity of the policy. Using revenues to cut tax rates has beneficial efficiency consequences but comes at the cost of higher regressivity. On the other hand, certain distributions have adverse consequences on both efficiency and equity. On these grounds, one cannot find an easy justification for the free distribution of allowances in a cap and trade system to industry. Of course, one can justify free distribution on political economy grounds. Our analysis helps illustrate the cost of using a free distribution to effect political goals.

Second, previous policy analyses have been carried out using models with a single representative agent or a small number of households. This analysis uses a model with a large number of households and therefore provides finer level detail on distributional impacts of various policies. Doing so makes the point that variation in impacts within broad socioeconomic groups may swamp average variation across groups.

Third, we provide two measures to proxy for lifetime income to address the criticism that studies using annual income bias carbon pricing towards greater regressivity. We do not find evidence of such bias in this analysis but stress that our proxy measures are by no means perfect.

Fourth, interesting variation in burden impacts exists across racial and ethnic groups. Such variation has not been pointed out in the literature before. Further work will be needed to understand the causes and implications of this variation. But our initial analysis suggests that much of the impact goes away once income and other household characteristics are controlled for.

Five, we note that sources side impacts of carbon pricing have typically been ignored in the literature. Doing so biases distributional studies towards finding carbon pricing to be regressive. We find that progressivity on the sources side is sufficiently strong to offset regressivity on the uses side so that carbon pricing is proportional.

Finally we note that advances in computing power and numerical techniques make solving CGE models with large numbers of households quite tractable. This paper provides a brief look at the possibilities for understanding differential impacts of policies across different socioeconomic dimensions. We expect that this will provide a new area for research that should improve our understanding of the distributional impacts of environmental and energy policies.

\section{Acknowledgements}

This paper grew out of a presentation made by Metcalf at the Fourth Atlantic Workshop on Energy and Environmental Economics held in A Toxa, Spain in July 8 - 9, 2010. The authors thank Tony Smith-Grieco for his invaluable help in assembling the CEX data. We acknowledge support of MIT Joint Program on the Science and Policy of Global Change through a combination of government, industry, and foundation funding, the MIT Energy Initiative, and additional support for this work from a coalition of industrial sponsors. 


\section{REFERENCES}

Armington, P., 1969: A Theory of Demand for Products Distinguished by Place of Production. International Monetary Fund Staff Papers, 16: 159-76.

Atkinson, A. and J. Stiglitz, 1980: Lectures on Public Economics. McGraw-Hill: New York.

Attanasio, O., 1998: Cohort Analysis of Saving Behavior by U.S. Households. Journal of Human Resources, 33: 575-609.

Ballard, C., 2000: How Many Hours Are in a Simulated Day? The Effect of Time Endowment on the Results of Tax-policy Simulation Models. Working Paper, Michigan State University.

Bovenberg, A. L. and L. H. Goulder, 2001: Distributional and Behavioral Effects of Environmental Policy. University of Chicago Press, Chicago, Chapter Neutralizing the Adverse Industry Impacts of CO2 Abatement Policies: What Does It Cost?, pp. 45-88.

Bovenberg, A. L., L. H. Goulder and D. J. Gurney, 2005: Efficiency Costs of Meeting Industry-Distributional Constraints under Environmental Permits and Taxes. RAND Journal of Economics, 36(4): 951-71.

Bull, N., K. A. Hassett and G. E. Metcalf, 1994: Who Pays Broad-Based Energy Taxes? Computing Lifetime and Regional Incidence. Energy Journal, 15: 145-164.

Bureau of Economic Analysis, 2007: Annual I-O PCE Bridge Matrix. Available at: http://www.bea.gov/industry/xls/PCEBridge_2002-2007.xls.

Bureau of Labor Statistics, 2006: 2006 Consumer Expenditure Interview Survey Public Use Microdata Documentation. Available online at: http://www.bls.gov/cex/2006/csxintvw.pdf.

Burtraw, D., R. Sweeney and M. A. Walls, 2009a: Distributional Impacts of Carbon Pricing Policies in the Electricity Sector. American Tax Policy Institute, Washington, DC.

Burtraw, D., R. Sweeney and M. A. Walls, 2009b: The Incidence of U.S. Climate Policy: Alternative Uses of Revenue From a Cap and Trade Auction. Resources For the Future, Washington, DC.

Davies, J. B., F. St. Hilaire and J. Whalley, 1984: Some Calculations of Lifetime Tax Incidence. American Economic Review, 74: 633-649.

Deaton, A., 2003: Measuring Poverty in a Growing World (or Measuring Growth in a Poor World). NBER Working Paper w9822.

Dinan, T. and D. L. Rogers, 2002: Distributional Effects of Carbon Allowance Trading: How Government Decisions Determine Winners and Losers. National Tax Journal, 55(199-221).

Energy Information Administration, 2009: State Energy Data System. Washington, DC.

Fernandez-Villaverde, J. and D. Krueger, 2006: Consumption over the Life Cycle: Facts from the Consumer Expenditure Survey. Review of Economics and Statistics, 89(3): 552-565.

Friedman, M., 1957: A Theory of the Consumption Function. Princeton University Press: Princeton, NJ.

Fullerton, D. and G. Heutel, 2007: The General Equilibrium Incidence of Environmental Taxes. Journal of Public Economics, 91: 571-591. 
Fullerton, D., G. Heutel and G. E. Metcalf, 2011: Does the Indexing of Government Transfers Make Carbon Pricing Progressive? NBER Working Paper No. 16768.

Goulder, L. H., 1995: Effects of Carbon Taxes in an Economy with Prior Tax Distortions: An Intertemporal General Equilibrium Analysis. Journal of Environmental Economics and Management, 29(3): 271-297.

Grainger, C. A. and C. D. Kolstad, 2009: Who Pays a Price on Carbon?

Hassett, K. A., A. Mathur and G. E. Metcalf, 2009: The Incidence of a U.S. Carbon Tax: A Lifetime and Regional Analysis. The Energy Journal, pp. 157-179.

Hyman, R., J. Reilly, M. Babiker, A. Valpergue De Masin and H. Jacoby, 2002: Modeling Non- $\mathrm{CO}_{2}$ Greenhouse Gas Abatement. Environmental Modeling and Assessment, 8(3): $175-186$.

Lyon, A. B. and R. M. Schwab, 1995: Consumption Taxes in a Life-Cycle Framework: Are Sin Taxes Regressive? Review of Economics and Statistics, 77: 389-406.

Metcalf, G. E., 2007: A Proposal for a U.S. Carbon Tax Swap: An Equitable Tax Reform to Address Global Climate Change. The Hamilton Project, Brookings Institution, Washington, DC.

Metcalf, G. E., A. Mathur and K. A. Hassett, 2010: Distributional Impacts in a Comprehensive Climate Policy Package. NBER Working Paper w16101.

Metcalf, G. E., S. Paltsev, J. M. Reilly, H. D. Jacoby and J. Holak, 2008: Analysis of a Carbon Tax to Reduce U.S. Greenhouse Gas Emissions. MIT Joint Program on the Science and Policy of Global Change, Cambridge, MA.

Metcalf, G. M., 1999: A Distributional Analysis of Green Tax Reforms. National Tax Journal, 52: $655-681$.

Minnesota IMPLAN Group, 2008: State-Level U.S. Data for 2006. Stillwater, MN: Minnesota IMPLAN Group.

Paltsev, S., J. M. Reilly, H. Jacoby, R. Eckhaus, J. McFarland, M. Sarofim, M. Asadoorian and M. Babiker, 2005: The MIT Emissions Prediction and Policy Analysis (EPPA) Model: Version 4. MIT Joint Program on the Science and Policy of Global Change, Report 125, Cambridge, MA.

Paltsev, S., J. M. Reilly, H. Jacoby and J. Morris, 2009: The Cost of Climate Policy in the United States. Energy Economics, 31: S235-S243.

Pechman, J. A., 1985: Who Paid the Taxes: 1966-85? Brookings: Washington DC.

Poterba, J., 1989: Lifetime Incidence and the Distributional Burden of Excise Taxes. American Economic Review, 79: 325-330.

Poterba, J., 1991: Is the Gasoline Tax Regressive? American Economic Review, 5: 145-164.

Rausch, S., 2009: Macroeconomic Consequences of Demographic Change: Modeling Issues and Applications, volume 621 of Lecture Notes in Economics and Mathematical Systems.

Springer Heidelberg-New York. 
Rausch, S., G. E. Metcalf, J. M. Reilly and S. Paltsev, 2010a: Distributional Implications of Alternative U.S. Greenhouse Gas ControlMeasures. The B.E. Journal of Economic Analysis \& Policy, 10(2).

Rausch, S., G. E. Metcalf, J. M. Reilly and S. Paltsev, 2010b: U.S. Energy Tax Policy. Cambridge University Press, MA, Chapter Distributional Impacts of a U.S. Greenhouse Gas Policy: a General Equilibrium Analysis of Carbon Pricing.

Rausch, S. and T. F. Rutherford, 2009: Tools for Building National Economic Models Using State-Level Implan Social Accounts. Cambridge, Massachusetts, MIT, mimeo.

Rausch, S. and T. F. Rutherford, 2010: Computation of Equilibria in OLG Models with Many Heterogeneous Households. Computational Economics, 36(2): 71-189.

Rutherford, T. F., 1995: Extension of GAMS for Complementarity Problems arising in Applied Economics. Journal of Economic Dynamics and Control, 19(8): 1299-1324.

Rutherford, T. F. and D. Tarr, 2008: Poverty effects of Russia's WTO accession: modeling "real" households with endogenous productivity effects. Journal of International Economics, 75(1): $131-150$.

U.S. Environmental Protection Agency, 2009: Inventory of U.S. Greenhouse Gas Emissions and Sinks: 1990-2007. Washington, DC. 


\section{APPENDIX A: Appendix}

This appendix describes the implementation of the decomposition algorithm that endogenously integrates the 15,588 households within the general equilibrium model.

We begin by describing our specification of household utility. Each household $h=1, \ldots, H$ is faced with the problem of allocating his budget to a set of commodities, to maximize utility. Let the quantities be denoted by $q_{i}$, for $i=1, \ldots, I$, corresponding to commodities with prices $p_{i}$, respectively. We assume that household utility is described by a utility tree whose structured in depicted in Figure A1. The utility tree consists of $N+1$ levels, $n=0,1, \ldots, N$; on each level we distinguish several utility components. At the highest level (indicated by $n=N$ ) of the utility tree there is only one component, which corresponds to overall utility; this component is a function of utility components at the next-lower level $n=N-1$. These utility components at $N-1$ are in turn each a function of disjoint groups of utility components at the next lower level $N-2$, and so on. Finally, the utility components at level $n=1$ are functions of the the elementary utility components. ${ }^{13}$

We specify the utility function by specifying the utility components (for simplicity we suppress the region index). We assume that all the utility components are linear homogenous CES-type functions of the associated components at the next lower level

$$
q_{n, i}^{h}=\left[\sum_{j \in i} \theta_{n-1, j}^{h}\left(\frac{q_{n-1, j}^{h}}{\bar{q}_{n-1, j}^{h}}\right)^{\rho_{n, i}^{h}}\right]^{\frac{1}{\rho_{n, i}^{h}}} \quad, \quad \rho_{n, i}^{h}=\frac{\sigma_{n, i}^{h}-1}{\sigma_{n, i}^{h}}
$$

where $j \in i$ is used to indicate the set of components $q_{n-1, j}^{h}$ associated with $q_{n, i}^{h}$, and where $\sigma_{n, i}^{h}$ denotes the elasticity of substitution between commodities $j \in i$. Note that we write the nested utility function in calibrated share form (Rutherford, 1995); $\theta$ and $\bar{q}$ denote the value share and consumption in the benchmark equilibrium, respectively. Additionally, we assume that $\theta_{n, i}^{h} \geq 0$, $0 \leq \sigma_{n, i}^{h} \leq \infty$, and $\sum_{j \in i} \theta_{n, j}^{h}=1$.

Labor supply is determined by the household choice between leisure and labor. We calibrate compensated and uncompensated labor supply elasticities following the approach described in Ballard (2000), and assume for all households that the uncompensated (compensated) labor supply elasticity is $0.1(0.3)$. Savings enters directly into the utility function which generates the demand for savings and makes the consumption-investment decision endogenous. Following Paltsev et al. (2009) we assume $\sigma_{C S}=0$.

The decomposition algorithm is implemented by replacing in each region the household side with a representative agent (RA) whose utility function exhibits the identical structure as

13 These are the sectoral outputs as labeled in the first and second columns in Table 1, and leisure and savings demand that enter in the two top nests of the utility tree. 
household utility in (1):

$$
Q_{n, i}=\left[\sum_{j \in i} \Theta_{n-1, j}\left(\frac{Q_{n-1, j}}{\bar{Q}_{n-1, j}}\right)^{\tilde{\rho}_{n, i}}\right]^{\frac{1}{\tilde{\rho}_{n, i}}} \quad, \quad \tilde{\rho}_{n, i}=\frac{\tilde{\sigma}_{n, i}-1}{\tilde{\sigma}_{n, i}}
$$

where upper case variables denote the respective counterparts for the RA to individual households as defined in (1). A key insight from Rausch and Rutherford (2010) is that the choice of $\tilde{\sigma}_{n, i}$ is entirely innocuous as this parameter bears no economic significance for the behavior of "real" households in the underlying economic model (it can, however, affect the convergence speed of the iterative solution procedure).

Given benchmark data on observable household demand $\bar{q}_{i}^{h}$ and prices $\bar{p}_{i}$, we initialize the RA general equilibrium model such that commodity demands are consistent with the aggregate of benchmark household demands. This is achieved by calibrating consumption $(\bar{Q})$ and value share $(\Theta)$ parameters as:

$$
\begin{aligned}
& \bar{Q}_{n, j}=\sum_{h=1}^{H} \bar{q}_{n, j}^{h}, \\
& \Theta_{n, j}=\frac{\bar{p}_{n, j} \bar{Q}_{n, j}}{\sum_{j^{\prime} \in i} \bar{p}_{n, j^{\prime}} \bar{Q}_{n, j^{\prime}}} .
\end{aligned}
$$

Solving for a carbon policy shock involves first solving the RA model to obtain a candidate vector of general equilibrium prices $\mathbf{p}^{k} . k$ denotes an iteration index. The second step solves a partial equilibrium relaxation of the underlying economy by evaluating household demand functions $q_{n, i}^{h, k}\left(\mathbf{p}^{k}, y^{k}\right)$, where household income $y^{k}$ is updated sequentially at prices in iteration $k$. The key step in each iteration involves "re-calibrating" preferences of the RA based on partial equilibrium households' quantity choices:

$$
\begin{aligned}
\bar{Q}_{n, i}^{k+1} & =\sum_{h=1}^{H} q_{n, i}^{h, k}\left(\mathbf{p}^{k}, y^{k}\right), \\
\Theta_{n, j}^{k+1} & =\frac{\bar{p}_{n, j}^{k} \sum_{h=1}^{H} q_{n, j}^{h, k}\left(\mathbf{p}^{k}, y^{k}\right)}{\sum_{j^{\prime} \in i} \bar{p}_{n, j^{\prime}}^{k} \sum_{h=1}^{H} q_{n, j^{\prime}}^{h, k}\left(\mathbf{p}^{k}, y^{k}\right)} .
\end{aligned}
$$

Note that this iterative procedure never alters preferences of the "real" households; it simply "re-benchmarks" successively the utility function of the artificial representative household to be consistent with the aggregated choices of individual households in each iteration. 


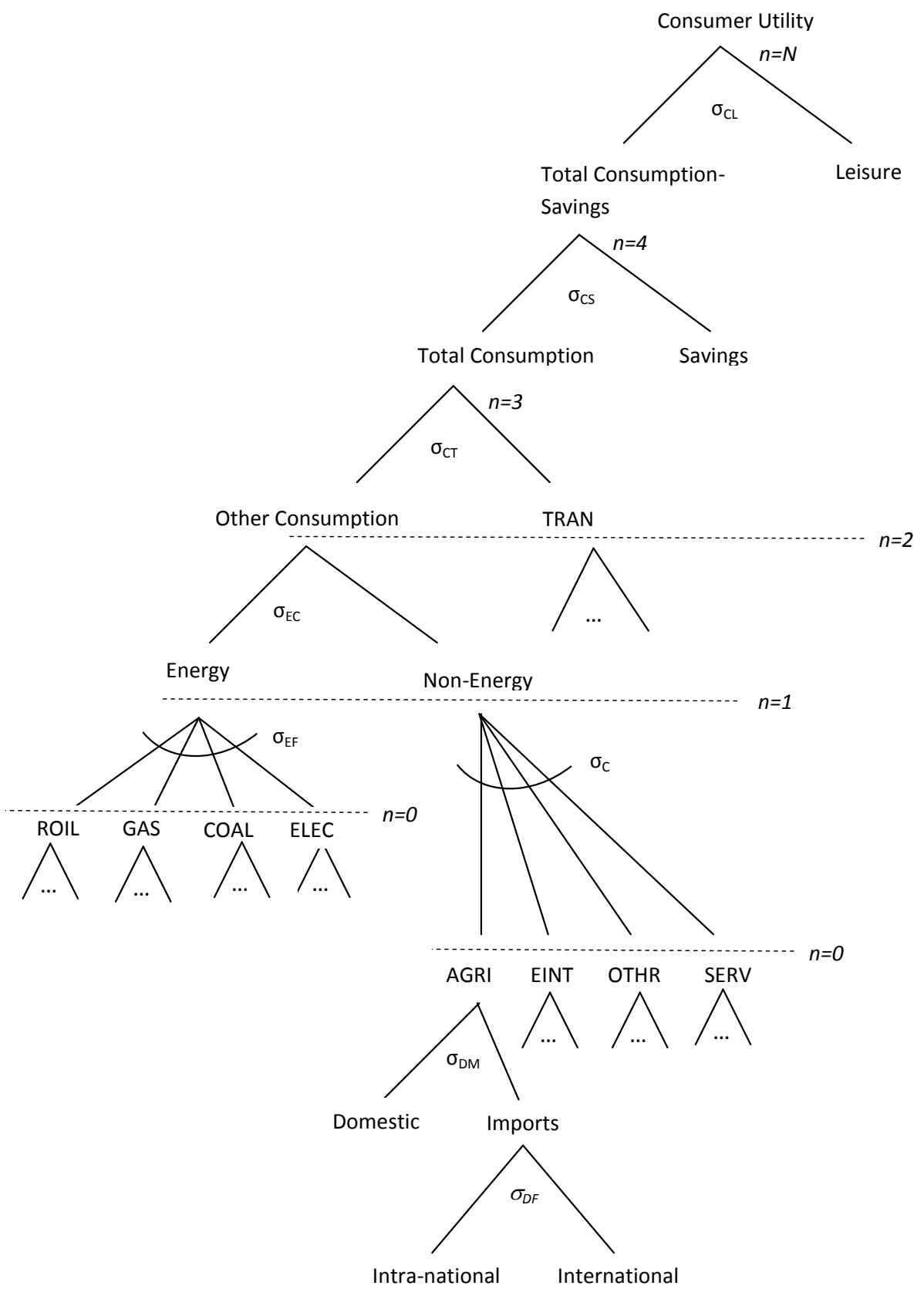

Figure A1. Utility nesting. 